\title{
UAV-Supported Forest Regeneration: Current Trends, Challenges and Implications
}

\author{
Midhun Mohan 1,2,*, Gabriella Richardson ${ }^{2}$, Gopika Gopan ${ }^{2}$, Matthew Mehdi Aghai ${ }^{3}$, Shaurya Bajaj ${ }^{2}$, \\ G. A. Pabodha Galgamuwa ${ }^{2,4} \mathbb{D}^{\circ}$, Mikko Vastaranta ${ }^{(\mathbb{D}}$, Pavithra S. Pitumpe Arachchige ${ }^{2} \mathbb{D}$, Lot Amorós $6 \mathbb{D}^{\text {, }}$ \\ Ana Paula Dalla Corte ${ }^{7}$, Sergio de-Miguel ${ }^{8,9} \mathbb{D}$, Rodrigo Vieira Leite ${ }^{10} \mathbb{D}$, Mahlatse Kganyago ${ }^{11,12}$ (D), \\ Eben North Broadbent ${ }^{13}$, Willie Doaemo ${ }^{2,14,15} \mathbb{D}$, Mohammed Abdullah Bin Shorab ${ }^{16}$ and Adrian Cardil ${ }^{8,9,17}$
}

\section{check for} updates

Citation: Mohan, M.; Richardson, G.; Gopan, G.; Aghai, M.M.; Bajaj, S.; Galgamuwa, G.A.P.; Vastaranta, M.; Arachchige, P.S.P.; Amorós, L.; Corte, A.P.D.; et al. UAV-Supported Forest Regeneration: Current Trends, Challenges and Implications. Remote Sens. 2021, 13, 2596. https://doi.org/ $10.3390 /$ rs13132596

Academic Editors: Mauro Maesano and Federico Valerio Moresi

Received: 7 June 2021

Accepted: 28 June 2021

Published: 2 July 2021

Publisher's Note: MDPI stays neutral with regard to jurisdictional claims in published maps and institutional affiliations.

Copyright: (c) 2021 by the authors. Licensee MDPI, Basel, Switzerland. This article is an open access article distributed under the terms and conditions of the Creative Commons Attribution (CC BY) license (https:/ / creativecommons.org/licenses/by/ $4.0 /)$.
1 Department of Geography, University of California-Berkeley, Berkeley, CA 94709, USA

2 United Nations Volunteering Program, Morobe Development Foundation, Lae 00411, Papua New Guinea; gabbyellabella@gmail.com (G.R.); ggopikagopan@gmail.com (G.G.); shauryabajaj1@gmail.com (S.B.); pabodha@tnc.org (G.A.P.G.); pavithrasaj.pa@gmail.com (P.S.P.A.); willie.doaemo@mdfpng.com (W.D.)

3 DroneSeed Co., 1123 NW 51st Street, Seattle, WA 25198, USA; matthew@droneseed.co

4 The Nature Conservancy, Maryland/DC Chapter, Cumberland, MD 21502, USA

5 School of Forest Sciences, University of Eastern Finland, 80101 Joensuu, Finland; mikko.vastaranta@uef.fi

6 Dronecoria, 03202 Elche, Spain; hola@dronecoria.org

7 Department of Forest Engineering, Federal University of Paraná-UFPR, Curitiba 80210-170, PR, Brazil; anacorte@ufpr.br

8 Joint Research Unit CTFC-AGROTECNIO_CERCA, 25198 Solsona, Spain; sergio.demiguel@udl.cat (S.d.-M.); adrian.cardil@udl.cat (A.C.)

9 Department of Crop and Forest Sciences, University of Lleida, 25003 Lleida, Spain

10 Department of Forest Engineering, Federal University of Viçosa, Viçosa 36570-900, MG, Brazil; rodrigo.leite@ufv.br

11 Earth Observation Directorate, South African National Space Agency, Pretoria 0001, South Africa; mkganyago@sansa.org.za

12 School of Geography, Archaeology and Environmental Studies, University of the Witwatersrand, Johannesburg 2050, South Africa

13 Spatial Ecology and Conservation Lab, School of Forest Resources and Conservation, University of Florida, Gainesville, FL 32611, USA; eben@ufl.edu

14 Department of Civil Engineering, Papua New Guinea University of Technology, Lae 00411, Papua New Guinea; willie.doaemo@pnguot.ac.pg

15 Morobe Development Foundation, Doyle Street, Trish Avenue-Eriku, Lae 00411, Papua New Guinea

16 Forest Resource Assessment \& Conservation Division, Ministry of Forestry, Suva, Fiji; mohammed.shorab@govnet.gov.fj

17 Tecnosylva, Parque Tecnológico de León, 24009 León, Spain

* Correspondence: mid_mohan@berkeley.edu

Abstract: Replanting trees helps with avoiding desertification, reducing the chances of soil erosion and flooding, minimizing the risks of zoonotic disease outbreaks, and providing ecosystem services and livelihood to the indigenous people, in addition to sequestering carbon dioxide for mitigating climate change. Consequently, it is important to explore new methods and technologies that are aiming to upscale and fast-track afforestation and reforestation $(\mathrm{A} / \mathrm{R})$ endeavors, given that many of the current tree planting strategies are not cost effective over large landscapes, and suffer from constraints associated with time, energy, manpower, and nursery-based seedling production. UAV (unmanned aerial vehicle)-supported seed sowing (UAVsSS) can promote rapid A/R in a safe, costeffective, fast and environmentally friendly manner, if performed correctly, even in otherwise unsafe and/or inaccessible terrains, supplementing the overall manual planting efforts globally. In this study, we reviewed the recent literature on UAVsSS, to analyze the current status of the technology. Primary UAVsSS applications were found to be in areas of post-wildfire reforestation, mangrove restoration, forest restoration after degradation, weed eradication, and desert greening. Nonetheless, low survival rates of the seeds, future forest diversity, weather limitations, financial constraints, and seed-firing accuracy concerns were determined as major challenges to operationalization. Based on our literature survey and qualitative analysis, twelve recommendations—ranging from the need 
for publishing germination results to linking UAVsSS operations with carbon offset markets—are provided for the advancement of UAVsSS applications.

Keywords: planting trees with drones; seed pods; unmanned aerial system (UAS); seed spraying drones; forestry applications of UAVs; afforestation and reforestation using UAVs

\section{Introduction}

Rapid upscaling of afforestation and reforestation (A/R) activities is required in many areas worldwide, especially in the most biodiverse biomes, such as tropical moist forests and other regions affected by climate-type forest disturbances (e.g., extreme wildfires), given the ongoing global changes that are partially caused by unsustainable anthropogenic activities, such as fossil fuel consumption and land-use land-cover change (LULCC) [1-5]. A study by Crowther et al. (2015) [6] has estimated the number of trees cut down every year to be at 15 billion, based on projected tree densities. This large-scale deforestation and degradation of natural habitats leads to the diminution of buffer zones, segregating humans and animals, thus increasing the probability of human-wildlife interactions and dissemination of zoonotic diseases [7-10]. As a consequence, it becomes paramount to look into novel forest replanting strategies to address deforestation. A possible pathway can be through forest landscape restoration (FLR) which includes planting trees in addition to agroforestry, erosion control and natural forest regeneration and this aids with reducing prospects of soil erosion and flooding, mitigating climate change and imparting ecosystem services and livelihood to the indigenous population [11].

Forest regeneration is the process by which new tree seedlings become established after a disturbance. Natural regeneration can happen in healthy or intact systems that have suitable seed sources, but this can be stochastic in both timing and density. Artificial regeneration strategies, consisting of a variety of intervention options, can be used to reduce the lag time between forest stands on a site, or simply to accelerate or set a trajectory while aiming to achieve the ecological objectives [12]. In artificial regeneration, it is important to select the most appropriate regeneration and site preparation techniques, as well as tree species that are suited to the site. These decisions will secure the establishment and early development of the seedlings in the regeneration area. In many forest systems, natural regeneration is often based on seed trees that are left on the site, or seed rain from proximal populations of tree species with animal or wind-dispersed seeds. The corresponding artificial regeneration practice is referred to as direct seeding, in which seeds are spread onto targeted areas over the area of interest, in a (semi) controlled manner, to facilitate the establishment of a new stand. A more reliable technique of artificial regeneration involves the nursery production of tree seedlings, to transplant them into the forest. Tree seedlings, either bare-root or containerized, are placed into the soil by hand or a machine. A two-person crew, experienced in hand planting, can typically plant 500 to 1500 seedlings per day, depending on the terrain complexity and previous site preparation. Whereas, using a mechanical planter and tractor, three people can plant around 4000 to 6000 seedlings per day [13]. Knowing how and when (i.e., what time of the year) to plant trees is crucial to their success. Prompt reforestation can be critical if a landowner's objective is timber production, carbon sequestration, and/or forested habitat restoration. Every year that a forest is understocked means a loss in timber growth and ecosystem services. Competing vegetation invading a site can result in the shift of a forest to a different successional trajectory, or can cause persistence of an early seral phase for many decades. Moreover, delaying regeneration can allow brush, grass, or other undesired vegetation to take over a site, making the process of establishing desired trees difficult and expensive. Furthermore, the forest practice laws of certain regions, such as Oregon, USA, have now started championing reforestation within a few years of a timber harvest [14]. 
Tree planting events provide excellent educational opportunities to participants across the globe $[15,16]$. Volunteer tree plantings, organized by conservation organizations and working groups, often provide room for effective collaboration, sharing knowledge and resources, and capacity building, which is essential for collective action in the battle against climate change. However, for larger landscapes, traditional tree planting procedures are not cost effective, and suffer from constraints associated with time, energy, and manpower [17-19]. There are practical limitations in the nursery industry, such as lag time to produce tree seedlings after a disturbance, energy, labor infrastructure, and seed availability [20]. Moreover, the limitations to fieldwork are now aggravated due to new challenges associated with COVID19-type pandemics, such as budget cuts, travel restrictions, and safety concerns [10,21-23].

From a strictly economic perspective, in several large-scale restoration efforts conducted in the past, a direct seeding has been preferred to nursery stock because it is less labor intensive and 10 to 30 times cheaper than planting nursery stocks [24]. However, there is around an 80 percent failure reported for individual seeds, and greater than 50 percent failure by the project to meet stocking targets [25]. Other difficulties associated with direct seeding, which result in a low plant establishment rate, are large-scale desiccation, predation, and wind erosion-ranging from a 10 percent emergence to outright failure $[24,26,27]$. A major issue with aerial-based seeding conducted with the help of broadcast machines, boom dispersing systems, sling pod buckets, airplanes, or helicopters is non-uniform seed deployment. This happens due to the irregular speed of the aircraft, jamming in hoppers, propeller or rotor wash, and the aerodynamic qualities of the seed [28-30]. Given these limitations, the use of state-of-the-art biotechnology methods in combination with remote sensing platforms, artificial intelligence (AI) and robotics sectors should be explored further, as this may increase the success rate of direct seeding operations.

In recent years, the advancement in the technology, machinery, and data processing related to unmanned aerial vehicles (UAVs; also known as drones) has revolutionized direct seeding operations [31-34]. Unlike the earlier aerial frameworks that focused solely on seed dispersals, the current UAV-powered endeavors emphasize optimizing locations for seed dispersal, manufacturing seed pods (or other vessels) for better seed germination, and monitoring seedling survival (more details in Section 3). Given that edaphic conditions limit seed establishment, especially after a disturbance, seed vessels are used in UAVsupported seed sowing (UAVsSS) endeavors. These are designed to draw a veil over all of the lacking nutrients in the planting location, and thus become a judicious choice, resulting in potentially higher establishment rates.

UAVsSS has found a variety of applications in the reforestation sector to date. For instance, this technology has been used to disperse seeds of mangroves in Myanmar and the UAE (United Arab Emirates), which can possibly foster marine life and biodiversity while mitigating coastal erosion if a high germination success rate is achieved [35-38]. Additionally, in parts of the United States, Canada, Australia, Madagascar, New Zealand, Spain, and Thailand, UAVsSS technology has assisted in reforestation operations in areas that are inaccessible or unsafe for humans, such as areas affected by wildfires [39-49]. The seeds of native plants have also been dispersed in deserts, depleted areas affected by logging, urban landscapes, and intensive agriculture units, using UAVsSS in countries such as the UAE and India [50-55] (more details in Section 4.4). In all these cases, the ability of UAVs to disperse seeds or seed pods 6 to 10 times faster than field-based transplanting efforts was highlighted by the respective service providers. However, there are also several pressing issues - such as the reduced resilience of planted forests, weather limitations, financial constraints, accuracy concerns, rules and regulations, and data processing challenges-that need to be considered (more details provided in Section 5).

Although UAVsSS technology has made considerable progress recently, with several success stories being reported by independent entities, academic literature dealing with this topic is lacking. Through this review article, we intend to extend frontiers of knowledge on the use of UAVsSS, by discussing recent advancements, ongoing applications, major challenges to operationalization, perspectives on various ideologies that are widely 
circulated, and future directions for accomplishing mass reforestation safely and sustainably, supplementing traditional and manual planting. The remaining part of the article is structured as follows: Section 2 describes the review methodology; Section 3 highlights the major steps involved in UAVsSS; Section 4 provides an overview of the current trends in UAVsSS; Section 5 discusses some of the major challenges to operationalization; Section 6 offers our perspectives and future directions for fostering the UAVsSS industry; and finally, Section 7 summarizes the takeaways of this article.

\section{Data Extraction and Qualitative Analyses}

\subsection{Methods}

In this paper, we aimed at reviewing all the major scientific articles, as well as nonscientific or grey literature including blogs, white papers, working papers, personal communication and conference presentations, with a focus on UAV-supported seed sowing and forest restoration starting from the year 2010. During the primary article selection phase, we used the search expressions presented in Table 1, in March 2021, and they were encoded in prominent databases such as Scopus, Web of Science and Google Scholar as well as Google search engine and applied to titles, abstracts and keywords; the first 30 search results were verified in each case. For locating relevant articles, the aforementioned expressions were adjusted for optimal concordance between articles and were verified with regards to the following keywords: "drones", "UAVs", "reforestation", "tree planting", "seeding" and "seed sowing". Although the focus of the study was on direct seeding, we had to include "tree planting" as a keyword and filter criteria as the majority of non-scientific articles were interchangeably using "tree planting" for "sowing seeds". This was later verified by reading the whole paper. Subsequently, during the secondary filtering phase, we excluded multiple versions of blog posts, articles not directly related to UAV-based endeavors (e.g., helicopter-based seeding) and articles associated with the agricultural sector since the study focus is on forest replanting. However, articles related to seed or seedling monitoring were retained as this is a major step in the post-monitoring phase. The finalized articles were classified based on their geographical zones (Asia-Pacific region, Americas, Africa, and Europe).

Table 1. Search expressions that were applied to titles, abstracts and keywords within the Google search engine, Scopus, Web of Science and Google Scholar databases as of March 2021.

\begin{tabular}{cc}
\hline Criteria & Search Expression \\
\hline What & "replanting" OR "forest regeneration" OR "reforestation" \\
How & "UAV" OR "unmanned aerial vehicle" OR "drones" OR \\
& "seed pod firing system" OR "seed spraying drones" \\
"seed sowing" OR "direct seeding" OR "seed dispersal" OR \\
"firing seeds" \\
When
\end{tabular}

\subsection{Results}

The primary article selection phase mentioned in Section 2.1 resulted in 219 matching results, out of which 92 were excluded based on the secondary filtering criteria (repeating information, no direct involvement of drones, agricultural applications, etc.). In addition, two non-scientific proceedings (unpublished report/personal communication) were added to the study. Among the 129 selected references, the citations associated with non-peerreviewed articles are specified separately in the reference section. Most of the studies focused on the countries of the Asia-Pacific region, followed by the Americas, Africa, and Europe, respectively. In total, we were able to locate 10 companies involved in UAVsSS activities, namely, DroneSeed, AirSeed, Flash Forest, Dronecoria, $\mathrm{CO}_{2}$ Revolution, Dendra (previously known as BioCarbon Engineering), Lord of the Trees, Marut GRO, CAFU, and Distant Imagery. Moreover, we were able to further classify the results, as follows, according to the type of applications: post-wildfire reforestation, mangrove restoration (including 
coastal erosion prevention), forest restoration after degradation, weed eradication, and urban or desert greening. All the selected articles were fully read and specific questions regarding the provided inferences were communicated and clarified with the UAVsSS company officials whenever possible.

\section{Forest Regeneration with Unmanned Aerial Vehicle-Supported Seed Sowing (UAVsSS)}

UAVsSS must be supported by strategic decision-making systems, and related infrastructural and technological requirements aiming to optimize the $A / R$ processes (Figure 1). These systems need to be fed with up-to-date data, such as information on topography, vegetation cover, height, and soil quality. Satellite imagery and lidar (light detection and ranging) can be used as ancillary data whenever possible, to map expansive areas, i.e., from landscapes to ecoregions, and create digital elevation models. UAVs are used to map the specific areas of interest at a very high resolution, i.e., up to millimeters of spatial resolution. In this case, structure-from-motion (SfM) technology has been proven to be very beneficial in creating high-quality orthomosaic and 3D point clouds [56-60].

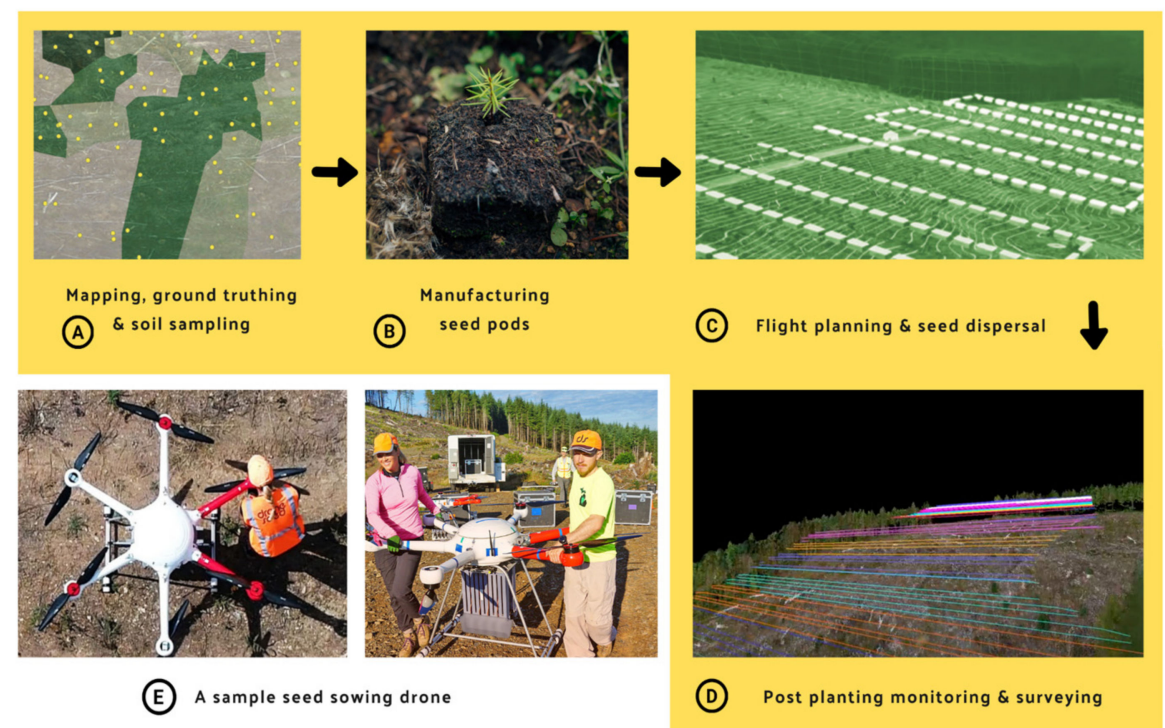

Figure 1. Basic stages of UAV-supported seed sowing (A-D); examples of a seed sowing UAV (E) (courtesy of DroneSeed).

Subsequently, by utilizing advanced AI in combination with site-specific historic data, various optimization algorithms are created/modified for identifying the optimal locations and species to plant [61]. Based on this calibrated information, flight plans are made, and swarms of UAVs are dispatched to the air for the automatic dispersal of seed pods; this way, we can replant trees in difficult areas that are otherwise inaccessible to field workers $[4,31,60,62]$. Herein, the seed pods are highly advanced capsules composed of nutrients and ingredients that ensure the seedlings' survival [44]. These might vary according to the species and targeted edaphic condition, and UAVs can carry combinations of various seeds when required. Based on the landscape of the selected microsite, the seed pods are fired with an intense air pressure that will allow them to penetrate the soil [25] (more information in Section 4.2), or dispersed with systems that do not require inertial inputs.

Once the seedlings are well rooted in the soil, the post-plant monitoring phase starts, and the UAVs help keep track of the regeneration success and the seedling's growth consistently; for more information on the monitoring processes, including various stateof-art classification techniques, please refer to [32,63-65]. Using spraying UAVs (e.g., DJI Agras), it is also possible to provide the water and nutrients (through fertilizers) that are crucial for the seedlings in their initial vegetation growth period. These spraying 
UAVs are usually large multirotor UAVs, and, from an experimental standpoint, the sector has witnessed technological advancements in recent years in countries such as China and India [66-68]. On the other hand, the seed dispersing UAVs come in a variety of sizes, which depend on state of the technology and the investment in the platform, and correspond to the legal regulations for the operating jurisdiction.

\section{Current Trends in Unmanned Aerial Vehicle-Supported Seed Sowing (UAVsSS) \\ 4.1. Identifying and Characterizing Locations to Sow Seeds}

With recent scientific advances, UAVs are increasingly being employed for forestry purposes, such as biometrics evaluation, edaphic condition estimation, canopy structural modeling, forest health monitoring and habitat assessments [57,69-73], and these applications are transferable to UAVsSS systems. An important step in the UAVsSS is to identify the site of the operation, for direct seeding using UAVs. Usually, aerial UAV surveys (utilizing multispectral and/or lidar sensors) are undertaken to assist with developing a methodology to deploy seeds over ground areas that are favorable for germination. Along with this, satellite data can also help with site analysis and selection. For instance, they can be utilized for determining fire perimeters and/or classes/severity of forest loss (by analyzing pre- and post-fire scenarios), and this can be incorporated as a parameter while selecting flight paths, dispersal intensities and seed types [74,75]. Moreover, in several cases, when partial cover image acquisitions occur (due to low lighting, wind speed, etc.) from UAVs, rather than redoing the flight surveys, classifications made from the satellite imagery can be used to fill in the data gaps.

Before seeding, some companies deploy light-duty UAVs with sensors that are capable of multispectral (especially NIR (near-infrared red) and RGB (red-green-blue)) and lidar data collection, to an area that is targeted for reforestation [76]. The data are then processed with proprietary software and aid in prescriptive practices, including site classification and species selection, then also for mission planning, which involves obstacle avoidance related to terrain and legacy materials (e.g., standing trees), identifying sub-optimal planting locations and gaining insights into vegetation and soil conditions, along with landscape features $[33,76,77]$. In other cases, conventional off-the-shelf systems are employed for surveys, or proprietary sensors are mounted to fixed-wing aircrafts. Similarly, topography characterization also varies by the company approach, technological capability, and by the need for each ecosystem. The high-resolution data sets that are collected in advance can assist with timing heavy-lift swarm operations and for developing nuanced prescriptions for mission planning, seed deployment, and are often provided to landowners for civil engineering and other biometric needs. These survey operations generally use large multirotor UAVs to fly over a site prior to heavy-lift operations for lidar and multispectral sensors, in addition to conventional imagery capture. Whereas, some companies follow a four-step process, beginning with ecosystem modelling to identify which species to plant where, manufacturing seed pods, using UAVs flying autonomously to plant seeds, and finally 'monitoring and proactive protection'. In the fourth stage, successfully established seeds and weeds that could be inimical to growth are identified, using artificial intelligence technologies [78].

\subsection{Seed Technologies for Enhancing Germination Success}

To increase the likelihood of seed germination, root egress, and plant establishment, without limiting the evolutionary potential of a particular species, an integrative approach to seed technology, by a thorough understanding of species-specific biological traits, such as seed morphology, dormancy requirements, and viability, in addition to site-specific biotic and abiotic conditions, is required. To improve the establishment rates in UAVsSS, several service providers are developing "vessels" that might assist with that process. Seed vessels assume that a seed is processed or manufactured to be surrounded with beneficial materials that aid in its dispersal and increase the regeneration success. A seed pod or seed vessel is a biotechnologically developed seeding method that is intermediate 
to the traditional direct seeding and nursery stock, which are deployed using UAVs to the microsite. A microsite refers to a small portion within an environment, exhibiting unique conditions, features or characteristics that can facilitate seed germination by moderating extreme biophysical conditions. For example, tree stumps are ideal microsites for seed germination in post-wildfire-affected areas, as the decaying wood will shade the seedling and provide nutrients [79]. The site-specific biotic and abiotic conditions will have an impact on the seed establishment after being deposited, and therefore, the seed coating creates an optimized edaphic condition within the microsite and around the seed that enables a higher likelihood of survival and early seedling development. The vessels can be designed for species and condition-specific needs, including the incorporation of a rooting substrate(s), nutrients, phytohormones, and mycorrhizal and bacterial symbionts, all of which can alleviate desiccation and other limiting edaphic conditions [33]. Additionally, to avoid predation of the seed methods, including olfactory and/or gustatory deterrents, camouflaging agents, and/or masking agents and a physical barrier to the seed coating, can be incorporated [33,80-82].

The design, configuration and components of seed pods are unique to each manufacturer, and the base materials (e.g., fiber-based pellet, plant-based deterrents, nutrients, and beneficial organisms), amendments, and configurations of seed pods vary with ecosystems and species. Irrespective of the size, homogeneous pods have the advantage of containing a uniform quantity of seeds, easier transport and deployment, and reliable behavior after deployment. Additionally, in some cases, seed pods are made by the thermochemical compression of soil additives, such as biochar, and are reported to be very light (less than $5 \mathrm{~g}$ ), thus optimizing the payload quantity; they are also strong and durable, which makes them invulnerable to breakage [83]. Moreover, in this case, most of these seed pods do not require pre-germination, because the nutrient-rich natural fertilizer provides them with resources, and sometimes drought endurance, and there is no need to bury them more than $2.5 \mathrm{~cm}$ due to their infusing nature [84,85]. Furthermore, the pod is also able to retain water after it rains, thus aiding with seed germination [78]. Nonetheless, for a scalable seed pod of a new configuration, a formidable manufacturing process is required.

A major limitation to scaling seed pod production is the availability of seeds. Each species will have highly variable collection and storage requirements, and this therefore adds complexity to the operational capacity of any manufacturing organization. There is also the need to create accountability along the supply chain, to ensure that seeds are collected responsibly, and that provenance is appropriately matched to the delivery site, and later tracked and reported to land managers. Further, tracking systems can be incorporated into UAV hardware and software, to account for the quantity, distribution rate, and deposition location of the vessels. This can be used for both broadcast and targeted deployment. In situations where suitable microsites are unavailable, seed pods can be randomly placed on surface areas and monitored in a semi-controlled manner, to gather more insights on the success rates [33].

\subsection{Speed, Scale, Cost and Safety}

The speed, scalability, cost effectiveness, and safety offered by UAVs may aid in supplementing traditional planting methods. UAVs can be remotely controlled, take an automatic flight path, circumventing obstacles by utilizing aerial and satellite data, possess greater maneuverability and precision (for instance through a real-time kinematic (RTK) centimeter-level positioning system), are easy for maintenance, storage and transportation, and have lower maintenance and usage costs [86,87]. Several enterprises in the sector have presented anecdotal evidence to indicate the speed of UAVsSS in forest restoration efforts. For instance, Flash Forest, a Canada-based startup company, has claimed to have the capability to plant 10,000-20,000 seed pods per day, and that their UAVs are capable of firing 200 seed pods into the ground in $160 \mathrm{~s}$ [40,88]. Meanwhile, Dendra's UAVs claim to have the ability to plant 120 seed pods/min, with each swarm covering 10 hectares a day, thus having the potential to plant up to 10 billion trees per year [89-91]. An Australian 
startup company, Airseed, has claimed the capability to eject two seeds/s, at speeds between 150 and $300 \mathrm{~m} / \mathrm{s}$ [92]. An emerging UAVsSS company, Lord of the Trees, claims that one of their UAVs can plant 160,000 seed pods in one day [93]. $\mathrm{CO}_{2}$ Revolution, a Spanish startup company, plans to plant 10 billion trees over 10 years [94,95]. Likewise, DroneSeed has claimed that its UAV reforestation is 6 times faster than a human involved in the same activity [96].

In theory, UAVsSS can be a cost-effective and high-output restoration method, as it can replace the costs associated with human labor, spread seeds much quicker than humans, and use beneficial compounds and resources more effectively [97-100]. In a similar vein, Airseed presents its UAV-based tree planting solution, which uses their UAV invention called the "podder", as it is $80 \%$ cheaper and 25 times faster when compared to manual planting [78,84,101]. On the other hand, Flash Forest aims to lower the cost of planting to fifty cents per tree [102]. Similarly, Dronecoria's goal is also to reduce the cost of traditional reforestation and make large-scale reforestation affordable, for less than one euro per tree [103]. In addition, the members of $\mathrm{CO}_{2}$ Revolution also claimed that seeds could be planted over one and a half soccer fields in approximately $10 \mathrm{~min}$ using UAVsSS technology, costing only 11 cents per tree [104]. Nevertheless, it will take another couple of years to validate the progress and success of these operations, given the constraints and uncertainties brought by environmental factors.

In regard to tree planting labor and scalability, UAVsSS can provide significant advantages. On average, humans burn calories equivalent to running two marathons in just one day of manually planting trees [105]. This can be easily minimized with the support of UAVs. Concerning scalability, the ability of UAVs to cover a greater ground extent and even large areas with rugged slopes in short time frames, which are not possible with manual efforts, places this approach in the spotlight. For instance, AirSeed claims to have covered 40 ha/day on average (planting 40,000 seed pods/day), using a single UAV operated by a two-man team, as opposed to covering 1 ha/day with manual planting [78,106]. In 2020, DroneSeed reported utilizing swarms of UAVs with a potential range of $\sim 11 \mathrm{~km}$, having an operation time between 8 and $18 \mathrm{~min}$, and with a payload capacity of $26 \mathrm{~kg}[33,107]$.

In terms of safety, UAVsSS offers multiple benefits, especially in inaccessible or dangerous areas, and may encourage regrowth in areas where natural regeneration is not possible due to land damage $[108,109]$. UAVsSS is also ideal when sowing seeds in areas with wet soil or rolling terrain, and because aerial seeding does not result in soil compaction, this method also assists in preventing soil runoff [110]. The pneumatic firing method also allows for seed pods to penetrate deep enough to cause effective germination, in comparison to manual planting. In addition, UAVsSS can also help with reforestation efforts in several other circumstances, such as post-fire conditions, and assist with spraying pesticides and watering in inaccessible areas [111]. UAVsSS technology would also eliminate the incurred damages when transplanting young trees, and strengthening root growth and tree strength overall [109]. Nonetheless, it is important to note that the speed, scale, cost, and safety of UAVsSS reforestation depend on several factors, such as the underlying technology, budget constraints, land-use pattern, and manufacturing material.

\subsection{Recent Applications}

UAVsSS technology has been used to disperse mangrove seeds, as this species has the ability to improve air quality, store large amounts of carbon, and foster marine life and biodiversity. Some companies have ventured into dispersing mangrove seeds in 2018 in Yangon, Myanmar using UAVsSS technology, and reported the mangrove saplings to be around 20 inches tall after a year [35,112,113]. Similarly, in February 2020, the UAE (United Arab Emirates) government launched a UAV-based mangrove planting project with the company Distant Imagery, along the UAE coastline, to mitigate coastal erosion, but the vegetation establishment outcomes are yet to be publicly reported $[36,53]$. In addition, there have also been partnerships with academic institutions such as the University of 
Technology in Sydney, to further develop UAVsSS technology to assist with mangrove reforestation in areas affected by wildfires [106,114-116].

Tapping into the ability of UAVsSS technology to reforest areas that may not be ideal or safe for human occupancy, such as areas affected by fires, DroneSeed has helped to restore forests that have been impacted by fires in California and Oregon, USA, using UAV "swarming operations" [39,117]. Likewise, Flash Forest has also dispersed tens of thousands of seed pods in areas of Canada's boreal forests, which have been affected by wildfires $[118,119] . \mathrm{CO}_{2}$ Revolution had also experimented using UAVsSS for forest regeneration efforts in Alto Tajo Park, Spain, where 200,000 square meters of land was burned as a result of forest fires [41]. In Australia, AirSeed has used UAVsSS technology to assist with bush fire restoration [114,115], and in response to Australia's devastating wildfires, the World Wildlife Fund (WWF) started a "Regenerate Australia Campaign", which is expected to adopt UAVsSS technology $[78,120]$. The capabilities of UAVs in longterm monitoring are beneficial in supporting post-fire ecological restoration and impact evaluation. In a recent study, Samiappan et al. (2019) [121] employed small UAVs, and performed immediate and long-term post-fire classifications on the area and volume of the burned regions, to estimate pre-fire health, post-fire damage, and track the vegetation recovery process of estuarine ecosystems. Herein, the authors underscored the advantages UAV-based approaches-in terms of turnaround time, spatial and temporal resolutions, and classification accuracy - have over satellite imagery-dependent methodologies. In fact, UAVsSS technology has also been used by Dendra Systems, in cooperation with the Lord Howe Island board, for weed monitoring [122]. Furthermore, weed eradication using bioherbicides and "smart spraying" is being investigated by a research unit in Chiang Mai, Thailand [45,123].

The seeds of native trees have been sowed in desert, urban and degraded areas, using UAV technology. A Dubai-based tech firm, Cafu, dispersed around ten thousand Ghaf (Prosopis cineraria) seed balls in the green belt of the Sharjah's Mleiha desert, in only a few hours using multi-rotor UAVs $[50,124]$. UAVsSS methods have also been used to restore greenery and regenerate depleted areas [125]. Civil UAVs have been developed to assist with the reforestation of cedar (Cedrus libani A. Rich) trees in Turkey [126]. Environment and Conservation Technologies (ECT) researchers in New Zealand have begun using UAVs to disperse native seed pods in areas such as pastures, exotic shrubs and wetlands, as part of a four-year project [127]. Similarly, a team of scientists from the Indian Institute of Science have previously conducted a UAV seeding trial over a 10,000-acre hill area along the river Pinakini and dispersed seeds of amla (Phyllanthus embilica L.), tamarind (Tamarindus indica L.), and several other native tree species [51,128]. Also, 10,000 seed balls, containing native species, such as roz, baheda, kher and kuntha, were dispersed in Udaipur, India during a pilot project conducted by the Indian government [129]. DroneSeed has also partnered with The Nature Conservancy to disperse seeds in order to restore the rangelands affected by invasive species, pasture rehabilitation areas, and erosion zones $[99,130,131]$. Likewise, Dronecoria have dispersed 100,000 Pinus nigra seeds in four hectares of Sierra de Maria-Los Velez National Park, an area that was depleted due to years of intensive logging and agriculture [132]. BioCarbon Engineering has also used UAVs to sow seeds of grasses and trees on abandoned coal mining lands in Australia [133,134]. Nevertheless, it is worth noting that the applicability of UAVsSS methods will only increase as UAV technology evolves and seed pods are developed for a variety of tree species.

\section{Major Challenges to Operationalization}

\subsection{Low Survival Rate of the Seeds}

One of the most important factors constraining the UAVsSS operationalization is that seeding is not suitable for all types of areas. The industry is still maturing, and only few companies are reporting UAVsSS project outcomes in peer-refereed or technical publications with specific seeding outcomes. A recent (2018) pilot project by DroneSeed demonstrated that the survival percentage of seeds was between 0 and $20 \%$ for certain 
conifer species. The establishment of seedlings was found to be limited by numerous factors (such as humidity, solar exposure, and predation) that affected the efficiency of the seed dispersal, germination, and growth [33]. As service providers advance and trial their technology, more reporting will improve the general understanding and applicability of this technology, with a data-based approach. Furthermore, extensive research is still needed to identify which species/shrubs in principle UAV-based A/R are more likely to be successful (e.g., pioneers vs. late-stage species vs. other dispersal types). Additionally, the limited availability of high-quality native seeds is a major problem worldwide and constrains UAVsSS operations equally $[27,135,136]$. The seed volumes used to treat areas may need to increase as an intermediary to major improvements in the efficacy of the seed technology. This will require sustainable seed sources, and robust processes to account for nuanced seed biological needs and site conditions.

\subsection{Future Forest Diversity}

Although UAV-based reforestation aims to re-establish the forest diversity and biodiversity that has been lost, it does not guarantee that a suitable ecosystem will replace the one preceding it. Based on the techniques, uneven seed distributions may occur during UAVsSS. In addition, issues in seed-firing accuracy may result in clusters of trees, which is not ideal, as the competition for limited resources will be increased. Even if seeds of multiple species are included in seed pods, only a few might be successful in germinating in particular unprepared terrains, and this may result in reduced resilience of the forests, to events such as droughts, due to a lack of forest hydraulic diversity; canopy tree density, and the coexistence of species can also influence tree regeneration patterns $[137,138]$. Despite the fact that a lot of the aforementioned drawbacks are commonplace with any other kinds of artificial regeneration methods, further research is required to analyze the varying degrees of impacts UAVsSS will have on forest diversity. All these factors further affect the returning biodiversity, as their habitat options are dependent on the structural diversity of forests with varying degrees of age classes and size classes. Nevertheless, it is worth mentioning that various enterprises have already initiated to make progress in this regard, and are expecting to plant up to 12 different species using gravity-fed systems in a single flight, highlighting the potential of utilizing UAV-based systems for more than planting just monocultures [78].

\subsection{Weather Limitations}

UAV operations are sensitive to weather conditions and might not be able to conduct the seeding and/or monitoring operations on particular days or seasons. Certain weather conditions, including high wind, precipitation and low temperatures, significantly reduce the operational efficiency of UAVs, and sometimes may damage their components $[139,140]$. Weather conditions may also place time restraints on the optimal conditions to conduct topographical UAV surveys. Variations in prime solar lighting times will affect the quality of the survey images. The timing of the UAV survey during climate seasons and climate anomalies will affect the data gathered regarding the best time for seed sowing, germination and forest regeneration [141]. This may result in poorly timed UAV sowing operations and an inaccurate assessment of environmental gradients. Low visibility and extreme temperatures will also affect the UAV operator and they will likely require additional gear.

\subsection{Financial Constraints}

UAVs used for seed sowing are not applicable to all types of seeding operations [142]. UAV models have been technologically modified from traditional models, to perform seed sowing-related tasks. Various parameters that might determine the design of UAV operations are specific types of forest, vegetation, canopy densities, energy sources, and previous land-use patterns. This might imply creating task-specific UAV swarms and/or seed germination vessels that combine conventional seeding methods with artificial regeneration [33]. These technologies also incur additional costs, such as durable high-power 
batteries, engineering expertise, and transportation costs. Although replanting and the related operations are cost effective for large-scale UAVsSS, the technology and equipment (e.g., UAVs, high-power lasers, 3D printing technology, manufacturing seed pods, licensing of pilots, the third-party limited liability insurance for UAV operations and registration for operations with regulating agencies) can often be expensive for individual landowners with a limited number of acres [142,143]. As technology advances, the operations might become more affordable, as has been seen in the agriculture and forest sectors, where UAVs are now being developed to reduce the costs associated with monitoring and spraying efforts [33,143-145]. Additionally, companies have taken measures to make their UAVsSS services cost effective and accessible, by charging for services per acre, offering free site survey, project-specific seed manufacturing services, tax exemption for sowing, and discounts based on carbon credits, and allowing small landowners to come into groups to reduce individual costs [77].

\subsection{Seed-Firing Accuracy Concerns}

Many UAVsSS companies advertise the speed and accuracy of their technology. Nevertheless, there are a few drawbacks to consider, such as the accuracy during seed sowing operations. Sowing seed pods in target areas is imperative, as the selected collection of microsites for UAVsSS operations takes into account a variety of biotic and abiotic factors to ensure the seeds germinate, and are viable and resistant [33]. Technical errors (even due to weather conditions) in GPS tracking, speed and altitude may inhibit the UAVs from dispersing/spraying seeds at the target area. In addition, the seeds dispersed by the UAVs may be swept away or blown if the wind speed increases. The risk of these accuracy drawbacks occurring increases when UAVs sow seeds on hills, slopes, or remote and hard-to-reach locations. Topographical planning for the best locations to sow seeds using UAVs often relies on open and free satellite imagery and lidar survey data [77]. Therefore, for UAVsSS to operate successfully, there may be a dependency on satellite imagery services from other companies. Using satellite imagery and other remote sensing techniques also incorporates their shortcomings into UAVsSS operations, thus increasing the risk of inaccuracy. As of now, several companies have forecasted effectiveness and staggering reforestation rates. For example, Flash Forest predicts they will plant 100,000 seed pods per day using two UAV operators, while Dendra predicts they will be able to plant 500 tree species by the year 2060 [89,146]. Despite these predictions, result-based data on the effectiveness of UAVsSS methods are quite limited. Therefore, more systematic studies are needed to derive meaningful inferences.

\subsection{Rules and Regulations}

UAVsSS is subjected to various aviation rules and regulations. For example, the United State Federal Aviation Administration (FAA) restricts the weight of a commercial UAV to $57 \mathrm{lbs}(25 \mathrm{~kg})$, and unless UAV pilots have a waiver exemption, pilots may only fly the UAVs within their "visual line of sight" [33]. The UAV limitations on technological capacity also restrict UAVs to a flight time of approximately $15 \mathrm{~min}$. Such regulations affect the UAV's ability to sow seeds over large areas. Therefore, the use of "swarm operations", which contain multiple coordinated high-capacity and autonomous UAVs flown by personnel on the ground, is a viable solution to accelerate seeding operations over large landscapes [33]. Swarm operations must also meet operational requirements and receive exemptions from regulations, which include consent to operate UAVs over extended distances beyond "visual line of sight" [33]. There are very few companies in this sector that have received government approval for UAVsSS. In fact, as of now, only one company in the United States has received approval from the FAA to fly heavy-lifting swarm UAVs beyond the visual line of sight, to reforest landscapes affected by wildfires [39,43,107,147-152].

As UAVsSS is an emerging sector, UAV regulations may vary regionally or may have never been implemented previously [153]. UAVsSS operations around conservation areas and national parks may also require exemptions and permits [154]. In addition, UAVsSS 
is subject to privacy laws, as these UAVs may easily capture data without the knowledge and consent of the general public (e.g., during hiking) it flies over [155]. Some nations have more stringent UAV-related privacy laws and UAVs may also face height restrictions in particular areas. These restrictions may complicate and delay the approval of UAVsSS reforestation efforts.

The safety and security of wildlife is an important factor to consider when using UAVsSS. The laws and regulations protecting wildlife amid UAV use vary internationally and can even result in criminal charges [156]. The presence of UAVs in the environment can disturb and elicit abnormal behavioral reactions from animals $[157,158]$. For instance, UAVs have been known to scare bird species away from migration grounds, disrupt nesting, interrupt feeding, and provoke bird attacks $[159,160]$. In addition, there is the risk of UAV collisions causing fires, which can be devastating for ecosystems. Therefore, though rules and regulations may slow the initial planning and operation of UAVsSS, strict rules and regulations must also be enforced to ensure the safe operation of UAVs in the environment, without the risk of reversals.

\subsection{Data Processing Challenges}

UAVsSS methods are subjected to UAV data processing challenges related to customization, accuracy and shareability. Given the multitude of options available for UAVs and SfM software packages, it is important to understand the impacts of flying height, resolution processing workflows (e.g., "high" versus "medium" in Agisoft PhotoScan) and processing parameter settings (e.g., the average number of tie points per image) on the SfM processing completeness and point cloud density attained before automating data processing workflows and creating specialized data pipelines [161]. The selection of optimal features can be quite challenging for complex forest environments with a lot of structural and compositional diversity, and might make the comparisons and/or merging of the disparate data products difficult and time consuming. For more information on how software characteristics influence processing time, we recommend readers to refer to Fraser and Congalton (2018) [161].

Processing high-resolution UAV data accurately is also a significant challenge in UAVsSS. Even if automated machine learning algorithms might provide quick insights on the location, development and implementation of standard quality assurance and quality control, this can take time and require human intervention, which increases the overall costs. If UAVs have to survey an area multiple times due to poor weather conditions or a software issue, there will be inaccuracies when combining the images, or duplicating or omitting elements of the area. Though software and technology exist for the aforementioned purposes, this may require combinations of multiple proprietary software, which may be costly and require additional expertise, and it may therefore be infeasible for smallscale landowners interested in the technology and smart farming techniques. In addition, surveying a remote and inaccessible area of land also increases the likelihood of data processing inaccuracies. If pre-calibration on the land is not possible before the survey, this could affect the accuracy of the images obtained [162]. In addition, there is a need to build more cloud environment-based collaborative tools for sharing and managing spatial "big data" in near real time [163].

\section{Perspectives and Future Directions}

\subsection{The Need for Transparency}

The drawbacks of the UAVsSS operations presented in this review must be openly and promptly articulated by companies. Transparency is essential for the public and the stakeholders involved, to understand the reality of UAVsSS's ambitious reforestation prospects. For achieving this, research assessing the efficacy of UAVsSS should be conducted, and the companies should evaluate the success of natural forest growth versus seed sowing methods, analyze seed turnover rate amid climate change, and take into account the biases and factors that could influence the measurements [164-166]. Steps towards transparency 
should include increasing publications of white papers, and strategic partnerships with academic and research institutions, which will not only demonstrate the reality of UAVsSS as a supplementary reforestation method, but its successes, failures and potentials. An example, in this regard, is a recent publication from DroneSeed, where the authors analyzed and reported the influence of site condition, species type, and seed treatments on the seed germination success rates of UAVsSS (Figure 2) [33]. Future studies could also be conducted to understand the role of the microclimate on the early development of seedlings and post-seedling germination mortality caused by insects and other animal species. This type of literature would perhaps introduce clarity and provide unbiased information to inform a detailed plan and the benefits of UAVsSS, in order to procure funding from crowdfunding initiatives as well as governments [167].
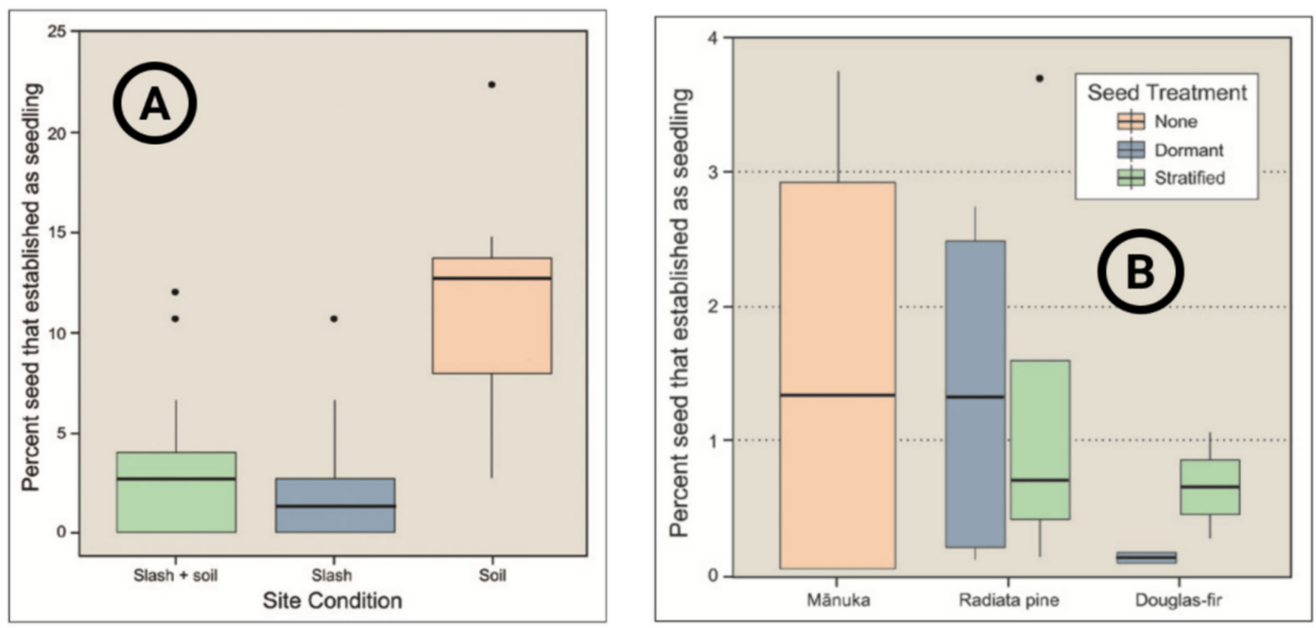

Figure 2. Results of UAVsSS pilot studies that investigated the influence of various factors on seed germination rates; site condition (A) and species types/seed treatment (B) (courtesy of DroneSeed; adopted from Aghai and Manteuffel-Ross, 2020).

\subsection{Open-Source Workflows for Increasing Community Engagement}

The industry could greatly benefit from increased communication between different specialists from sectors such as forestry management, nursery, ecology, terrestrial robotics, landowners, NGOs, and governments [88]. This would foster dialogue between specialists and professionals and allow for feedback to encourage the innovation of solutions in this industry. For example, Madagascar's government has acquired UAVs for reforestation experimentation, in order to address deforestation [168,169]. Also, the forest department of Haryana in India has agreed to test UAVsSS technology in the Aravallis [170-172]. Dronecoria supports open-source knowledge and youth engagement activities, by running summer intern programs in Spain that focus on application development (Dronecoria internal communications). Additionally, the company promotes a one hundred percent opensource UAV sower, seed dispensers, and seed enhancement machines, such as priming and coating, which are easily replicable for a low cost, and they encourage the concept of open-source DIY (do it yourself) science by making their UAV designs publicly available (see Figure 3) [173-175]. This could address a lot of the drawbacks related to the technology accessibility and cost of UAVs used for seed sowing [176]. To improve the cost and time associated with UAV image and map processing, it would be a suitable idea to get people who own UAVs to share data they have collected from areas with UAVsSS companies. In addition, encouraging the public to create their own seed pods using simple materials, such as clay, manure and soil, would be cost effective and assist in making UAVsSS methods more widespread [51,177]. Increasing the participation of such stakeholders, perhaps even universities and especially local populations, would also empower these groups to get involved in the technology aspects of UAVsSS and increase the locations of UAVsSS applications. For example, a forest restoration research unit has been established 
in collaboration with Chiang Mai University in Northern Thailand, and it has assisted with the reforestation of land depleted by crop farming and wildfires $[45,122]$. These stakeholders could improve seed collection strategies, seed enablement technology, and the sustainability and biodegradability of the seed pod packages used [178-180]. Moreover, the setup and running of large-scale UAVsSS operations often use funding from a variety of sources, such as forestry companies, government contractors, mining companies, and donations from the general public [102]. Hence, to make UAVsSS cost effective, creating funding initiatives that subsidize the costs of small-scale reforestation technology using UAVs is required; increasing the incentives for landowners and firms, and attracting the interest of the general public to invest in these would also be beneficial [181,182].

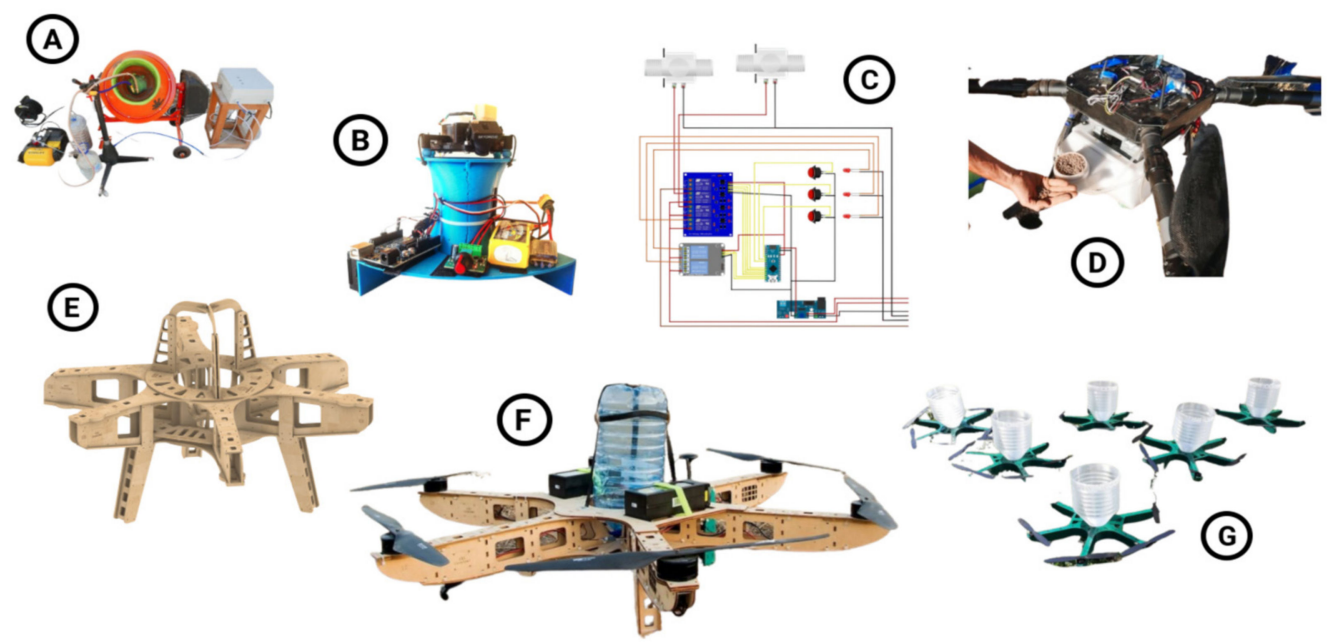

Figure 3. Example of DIY planting UAV components: automatic seed coater (A); seed spreader (B); schematics of the seed coating controller (C); tank with coated seeds to perform aerial sowings (D); wooden frame of the UAV (E); a sample seed sowing UAV that was made locally (F); and a swarm of small-sized miniature UAVs for inspiring kids (G) (courtesy of Dronecoria).

\subsection{Educational Resources, Awareness, and Integration with Existing Field-Based Tree Planting}

Recognizing the advantages of both field-based techniques and UAVsSS would allow the effective integration of techniques for a better outcome. There are interactive tree planting programs that provide hands-on learning opportunities for children and youth, developing the next generation of land stewards [183]. Therefore, UAVsSS should not be interpreted as a replacement for field-based tree planting, but rather be considered as supplementing the existing efforts. However, if planned strategically, UAVsSS could enrich the values of manual tree-planting endeavors. The integration of existing volunteer tree planting events with UAVsSS, and organizing global coding challenges, would provide opportunities for children and youth, with different interests and skills, to contribute innovative solutions to the A/R initiatives. Academic courses, massive open online courses (MOOC) and training programs, with hands-on practical components, can also be effective in disseminating knowledge on UAVsSS-related technology and its significance. Additionally, establishing new types of collaborations between universities, NGOs involved in large-scale tree plantings, and private industries specializing in UAV-based technologies would create new opportunities for internships and employment.

\subsection{Better Understanding of Forest Behavior under Climate Change}

Planting trees has increasingly been identified as a natural climate solution, with a great climate mitigation potential globally [184]. However, the climate would continue to change, even with the strongest mitigation efforts [185]. Warming temperatures, climateinduced droughts, heightened pest and disease stresses, and increased abundance of invasive species would all impact the future forests. Therefore, integrating climate-informed 
planning (e.g., prioritization of drought-tolerant species, modeling of predator population expansion based on temperature hikes, optimizing seedling monitoring frequency with respect to seasonal shifts) to UAVsSS efforts would increase climate resilience and enhance the adaptive capacity of the forests that are regrown [186].

Understanding the predicted responses of tree species to climate change would enable the selection of tree species with the best-suited genetic material to withstand future stressors [187]. Certain species are predicted to shift their natural ranges in the face of climate change, and facilitate ecosystem transition by adopting climate adaptation strategies, such as preferred assisted migration in certain ecosystems [188]. The effective implementation of these strategies, following a holistic approach to land management, such as the Miyawaki method, is important to enhance landscape-scale diversity and climate resilience [189]. UAVsSS is a promising technological innovation, with its maximum potential yet to be discovered. Nevertheless, due to its novelty, long-term field data are limited. As a solution, seed performance assessments can be conducted in the northern and southern hemispheres, simultaneously, to generate data representing two growing seasons [33].

\subsection{Linking with Carbon Markets}

Efforts should be made by the enterprises involved in UAVsSS to tap the potential of existing policies, schemes and related benefits, to attract potential customers, aid climate change mitigation endeavors, gain incentives, and simultaneously increase the technologies' adoption/utilization across the globe. An important step in this direction could be to incorporate and link the existing market mechanisms, for instance, the carbon market, which soared to an all-time high of $€ 229$ billion in 2020 [190]. Additionally, with various countries, such as China, Japan, South Korea, along with the EU, setting goals for greater emission reduction targets/carbon neutrality, and China, the EU, and the UK developing/launching their own emission trading scheme/systems (ETS), the carbon market presents a great opportunity for firms to leverage [191,192].

The enterprises involved in UAVsSS are thus encouraged to get in touch with the necessary authorities and stakeholders in this regard. For instance, the Climate Action Reserve, a carbon offset registry for the North American carbon market, has already initiated to issue carbon credits for reforestation projects to UAV-based firms, such as DroneSeed, which then offer a part of the carbon credit sales to its clients $[96,193,194]$. Such initiatives will not only strengthen the existing market mechanisms-aimed at climate change mitigation in alignment with various United Nations sustainable development goals (SDGs) and programs, such as REDD+—but will also encourage enterprises, private entities, landowners, and individuals to undertake UAVsSS for reforestation/afforestation/other purposes. This will simultaneously encourage participation in (voluntary) carbon markets, reduce the overall cost of the operations, and strengthen the existing infrastructure.

\subsection{Development of Unmanned Aerial Vehicle (UAV) and Robotics Technologies}

For cost effectiveness, an important requirement is the development of multi-purpose, yet situation-specific, UAVsSS mechanisms. Currently, multiple UAVs are being used for performing individual operations-such as mapping (multispectral UAVs), 3D modeling (lidar UAVs), tree planting (custom made heavy-lift UAVs, weighing more than the 55 pound maximum for a conventional UAV) and irrigation (pesticide/water spraying UAVs) [111]. However, having an all-in-one UAV kit, with parts that can be selected based on the phase of plant growth, can be extremely beneficial. This will encourage landowners to invest in this technology, seeing the long-term investment/return value. In recent years, there have been technical advances on prolonging the airtime of UAVs using solar power [195], hybrid fuel cell systems [196], and petrol-electric hybrid systems [197]. Such developments can have potential applicability in the field of UAVsSS. Therefore, investing further in understanding the tradeoffs between solar power generation, charging cycle durations, and motor power consumption, and taking advantage of advances in carbon 
fiber technology, is recommended. Making the process more energy-efficient will also help cut the costs and fire risks related to battery transportation tremendously. Improving UAV energy sources, such as looking at wireless charging solutions, would decrease the downtime and improve the seeding operations in the field [198]. Payload manipulation and waypoint optimization, through interfacing with state-of-the-art flight controllers, can also help to improve planting patterns and reduce the overall cost [199].

As different countries and locations have different needs, in terms of climate change mitigation, type of species, and post-disturbance locations to plant, it is important to integrate different scientific perspectives from various nations, to help optimize UAV developments that are needed in the reforestation sector. This can include engaging with government representatives to influence the introduction of flexible importing and exporting rules related to technologies such as lidar, which are currently barred in several countries. Better policies, rules and regulations can ensure safety and legality, which is a prerequisite for the successful proliferation of UAVsSS services. Recently, UAV swarms have been utilized to accelerate sowing efforts; however, this further complicates the technological advancements, maneuvering skills, and policy leeway needed. Investing in improving the mechanical parameters for having better control and accuracy on, among others, speed and angle, may present heavy-lift UAVs as more attractive to the forest landowners who are new to the technology. Further research on handling heavy-lift UAVs in night mode, and the development of online spatial database management (where field workers can communicate, and share collected data with program managers in real-time) is also recommended.

\subsection{Precision Forestry and Data Fusion}

The transformation from traditional forest management, relying heavily on manual and analog processes, to precision forestry systems, with digital data integrated planning, detailed management, and operationalization, has gained some momentum over the last decade, and can be integrated with UAVsSS in the future [200]. These advanced technologies have the potential to revolutionize natural forest management and support large-scale UAVsSS initiatives, by helping them minimize the time spent on planning, implementation, and monitoring activities. With a main focus on the forest industry, Choudhry and O'Kelly (2018) identified fifteen promising practices in precision forestry, and most of them can be applied in UAVsSS initiatives, such as advanced genetic improvement, automated nurseries, site-specific management, fire monitoring, pest and disease monitoring, digital inventory, field support tools, forestry planning models, e-dashboards, and advanced analytics with data fusion [200].

Data from Earth observation missions, such as NASA GEDI, ECOSTRESS, and other space-borne sensors (e.g., Sentinel-1 and -2), can be used in the decision-making process, to identify high-priority areas for reforestation, and have the potential to upscale operations to global levels [201,202]. Post-restoration monitoring is another aspect of precision forestry that can be translated into UAVsSS. UAV-mounted sensors can be used to conduct various assessments, including regeneration success, photosynthetic activity, post-drought stress, pest and disease stress, and invasive species abundance and competition [203-206]. This information would facilitate timely decision making, and is an important step in adaptive management. Additionally, software applications should be made that will allow the forest landowners to roughly estimate resource needs and the cost for tree planting, based on environmental- and management-related factors. Making this information available up-front, in a user-friendly manner, would improve the transparency, and thereby provide a nudge to make an informed decision to adapt. Recent research and technology have emerged to provide UAV micro-weather forecasts and monitoring.

The issues associated with weather can also be addressed, with the support of stateof-the-art technologies. UAV pilots and operators require proximate, low-altitude weather forecasts accounting for various weather parameters to operate successfully, although the current weather forecasts in several countries often do not provide high-resolution 
and accurate data, as these forecasts are often conveyed in hour-long increments at high altitudes [207]. Therefore, it is evident that UAVsSS reforestation efforts need to utilize UAV-specific weather forecasting technology to operate successfully, and we can expect the proliferation of more apps such as UAV Forecast in the near future. Another example is the instaClimaCell Weather API, which provides historical real-time micro-weather forecasts around the globe, which improves the preparation, duration and analysis of UAV flights.

\subsection{Improving Seed Supply Chain Management}

Although UAVsSS should not be treated as a means to replace the seedling nurseries, they hold the potential to efficiently fill the gaps in the current field-based reforestation goals. Technology development, government support (incentives and subsidies), market diversification, regulations for seed quality, implementation of community-based participation and seed exchange programs, and workforce improvement are strategies to advance the seed supply chain $[20,135,208]$. Integrating discussions on UAVsSS into the aforementioned processes can help reduce the pressure on field workers, and also create new job opportunities and awareness in the technological sector.

The COVID-19 pandemic has aggravated the challenges associated with the seed supply chain. Therefore, companies can sell seeds in bulk quantities to large-scale processing centers, since the process can be quicker and safer compared to multiple small-scale operations. Also, by understanding where UAVsSS can be a viable alternative to traditional methods, it is possible to geographically optimize the distribution of limited seeds and human resources. To minimize the emission of greenhouse gases during supply chain management (due to the use of non-renewable energy sources), attention should be paid to the use of low-carbon renewable energy sources (such as solar power and wind) to reduce the carbon footprint, and the incorporation of UAVs could help significantly when scaled to a higher margin.

\subsection{Relation with United Nations Sustainable Development Goals (UN SDGs)}

UAVsSS is associated with 4 of the 17 interconnected UN sustainable development goals, namely, SDG 9 (industry, innovation, and infrastructure), SDG 13 (climate action), SDG 14 (life below water), and SDG 15 (life on land). Therefore, supporting the evolution of the UAVsSS sector safely and securely would help boost the efforts of the UN SDGs. In practice, such a generalized approach can be traced into areas such as the following:

- Mangrove forests are one of the world's most endangered and critical ecosystems, and they are very important as they provide coastal protection from storm surges, maintain our climate, control floods, and stabilize coastline [209-213]. Although UAVs have become a convenient tool for conducting area assessments and biomass mapping of mangroves [214-216] in countries such as Costa Rica, Australia, and Malaysia, their potential to help with mangrove reforestation is yet to be explored. In this aspect, a UAV-powered project was initiated by the Ministry of UAE in 2020, to plant more mangroves along the UAE's coastlines, aiming to protect its shores from the rising sea levels and boost fish stocks [36]. With further research and support from ecologists and other conservation agencies, we can expect more UAV-supported blue carbon conservation projects supporting UN SDG 14 (life below water) [217];

- The UAVsSS industry can support SDG 9-fostering innovation, infrastructure and industry-by educating the local communities on the technological processes and skills entailed in UAV use and seeding operations. The local communities may then apply these valuable occupational skills to agroforestry and regenerative agriculture projects, and use them to achieve higher-paying jobs for maintaining better standards of living [134]. The successful examples of FAO-powered UAV workshops and initiatives for forest monitoring and risk assessment in countries such as Mozambique, through partnerships with national counterparts, encourage us to look into the possibility of using UAVsSS endeavors for supplementing the ongoing large-scale afforestation programs, such as the Great Green Wall [218]; 
- The concept of UAV usage also found positive reviews during the growing problem of finding laborers during the COVID-19 crisis. For instance, UAVs have been used to spray disinfectants in public places during COVID-19 [219], and the same situation is extrapolatable to the A/R sector as well, as described in Mohan et al. (2021) [10]. Relying on state-of-art technologies in this scenario will not only contribute to the reduction in the safety concerns and human contact, while engaging in $A / R$, but will also provide a suitable alternative for tracking the progress of previous $\mathrm{A} / \mathrm{R}$ initiatives, and keep a check on illegal logging activities.

\subsection{Addressing Systematic Bias during the Transition}

A focus on inclusivity in the UAVsSS industry, including the promotion of gender equality, indigenous issues and rights, and the inclusion of developing nations, will increase growth, perspectives, cooperation, and address systemic biases in the UAVsSS industry. The development of UAVs and the robotics technology used for UAVsSS should be accessible and affordable throughout the world, rather than being dominated and controlled only by developed nations. It is also necessary to ensure that UAVsSS projects are not used as carbon credit loopholes by the developed countries, in order to continuously use fossil fuels. New ways to utilize carbon offset projects in indigenous territories, to transfer funds to local peoples, should be thought about. An emerging UAVsSS company, Lord of the Trees, specifically commits to transparency, and recognizes indigenous ancestral land legacy and ethical social responsibility in their reforestation efforts [220]. Such principles should be at the core of UAVsSS operations, in order to address systemic bias in the industry.

\subsection{Dissecting the "Plant a Billion Trees" Propaganda}

The main objectives of UAVsSS companies include using UAV technology to accelerate reforestation efforts, especially on a large scale and across remote areas, while reducing the human labor required [221]. Throughout this review, we found that several articles frame the emergence of the UAVsSS industry in light of the statement "we will plant a billion trees by ..." ". Even if the trajectories of UAVsSS operations may indicate this is achievable, we must critically evaluate whether this is feasible, and if it is in the best interests of our environment and climate.

Every year, 10 million hectares of forest are lost [222]. Nations and organizations have made commitments to plant one to two billion trees over one to two years $[223,224]$. Businesses and companies have been increasing their investments in reforestation technology innovation, UAVsSS, and multi-purpose UAV-based industries [225-228]. Research indicates that reforestation may be the fastest way to address climate change and remove $\mathrm{CO}_{2}$ from our atmosphere in several areas $[229,230]$. However, we must also consider that the benefits are not immediate; tree planting on such a massive scale will also entail years for trees and forests to mature [231]. This means that economic services, such as logging, and timber supply will not be available immediately.

In addition, the ecosystems and biodiversity housed by forests that have been lost will not be reestablished quickly, or be the same as they were before, and this is a major factor contributing to forest resilience against natural disturbances and climate change. It is also important to consider that not every landscape needs to be reforested, rather, some areas are better left open. Some reforestation efforts undermine the importance of open areas, and planting trees in areas such as grasslands, rangelands and peat bogs would reduce the biodiversity and resilience [232]. Similarly, adding forested areas to deserts will add warmth, water, and plant biomass to the area, and create ideal breeding conditions for insects such as the desert locusts, which may disrupt the equilibrium of the ecosystem, the carbon levels, and the agricultural and food systems [233]. Forested areas also may not be suitable to all species; in fact, open areas are preferred habitats for animals such as African wild dogs [234]. Thus, such information must be taken into account when evaluating the long-term goals of the UAVsSS industry. 


\subsection{A Roadmap for Future Large-Scale Reforestation}

It is important to consider the impact UAVsSS will have on forests grown in the future, including landscape-scale diversity, forest composition, density, and the prominence of certain native species. Local communities and indigenous populations have been guardians of the forests for years; therefore, their community's responses to UAVsSS must also be taken into account, in order to have sustainable reforestation [235]. The introduction of such operations in remote indigenous communities may be reminiscent of foreign presence in forests and communities for some, which has historically been invasive and destructive. As previously noted, UAVs also risk disturbing the wildlife during reforestation operations. In addition, flying UAVs may intrude upon the privacy of communities in the vicinity of a target reforestation area. Therefore, UAVsSS companies should conduct surveys to assess the social impacts and concerns.

UAVsSS has a great potential for long-term and large-scale reforestation efforts. The technology should continue to be used for remote and difficult-to-access areas, such as those affected by wildfires, as well as for post-drought, logging and erosion-prone areas. In fact, using UAVsSS may prevent the risk of mudslides, ecosystem destruction and erosion, which usually occur during the interim time between forest fires/deforestation and manual planting of new saplings [236]. In an era of post-COVID-19 recovery, UAVsSS should also be incorporated into worldwide "green recovery" plans [237]. This technology will help to build back forests, which are important in reducing the human-pathogen exposure that leads to the spread of zoonotic diseases such as COVID-19. In addition, there is not only a need for a long-term environmental assessment of the trees planted using UAVsSS technology, and their surrounding areas, but also on how the level of biodiversity, the soil quality, and the wildlife in an area may be impacted by trees planted using UAVs. For example, seedlings planted in areas with high levels of dead biomass from previous fires may have higher rates of mortality in the case of future fire events, whereas some species need fire-prone ecosystems to thrive.

UAVsSS methods should be articulated as a valuable supplementary tool that may assist reforestation efforts. By the year 2030, cities are expected to cover three times more land, therefore destroying biodiverse ecosystem hotspots [238]. In this case, UAVsSS should not be used as an opportunity to justify urbanization and the forest/ecosystem loss that it ensues. There are also risks to be considered if UAVsSS becomes intertwined with carbon offset projects and capitalism [239]. Thus, this UAV reforestation technology should not be marketed as an all-encompassing solution to climate change, but a complimenting process that addresses gaps in the existing response, while working alongside traditional conservation and tree planting efforts.

\section{Conclusions}

UAV-supported seed sowing has gained the attention of a wide audience-including academics, forest managers, restoration practitioners, policymakers, landowners, environmental conservationists, remote sensing scientists, and biotechnology researchers-due to its ability and potential to be utilized as a successful revegetation/stabilization tool that can supplement the ongoing traditional A/R programs and practices. The applications of UAVsSS were primarily found to be in areas of post-wildfire reforestation, mangrove restoration, forest restoration after degradation, weed eradication, and desert greening. Efficiency, ability to employ in unsafe (e.g., wildfire-affected areas) and inaccessible areas (i.e., remote and high-terrain areas), cost-effectiveness (e.g., cost of planting stocks) in large-scale operations, as well as an alternative to limited labor, time and energy, especially during times similar to the COVID-19 pandemic, are the main benefits associated with UAVsSS. Furthermore, recent and ongoing advancements in software, hardware and standard operating procedures allow us to seamlessly and successfully undertake surveys, develop swarm flight plans, and identify areas for seeding and payload delivery. However, while implementing UAVsSS, careful attention should be paid to site/species selection, to optimize seedling germination/establishment and the regrowing forest diversity. In addi- 
tion, environmental policies, rules and regulations, waivers of line of sight and payload, the substances used in coating/pelleting/seedling packaging, post-monitoring to determine the survival and turnover rates, as well as battery/transportation/storage facilities should also be given proper consideration.

Open discussions on UAVsSS facilitate advancements in science and create awareness among people which would help promote sustainable ideas and decisions in restoration projects. Diversified forest systems enhance carbon sequestration in biomass and soil, and serve as a mitigation and adaptation option to climate change, along with providing a wide variety of ecosystem services. Despite the myriad of benefits associated with UAVsSS, it should be considered only as a complementary method, and not as a replacement for traditional planting methods. Also, we advise the readers to keep in mind that many of the aspects discussed herein reflect the opinions of UAVsSS users as well as the interpretations drawn by the authors from the existing literature-of which a major portion is comprised of grey literature-given the paucity of publicly available data on operational studies. Nonetheless, with time we can expect to witness more practical uses of this technology, with it being compared and contrasted with the results from the scientific research and development field. Though this review mainly targets the academic audience, we anticipate this will be equally beneficial to a broader community, encompassing restoration practitioners, UAV enthusiasts, and the common people who are interested in familiarizing themselves with UAVsSS applications and their future possibilities.

Author Contributions: M.M.: conceptualization, writing — original draft, review and editing, methodology, data curation, formal analysis, graphical illustrations; G.R.: writing - review and editing, data curation, formal analysis; G.G.: writing - review and editing, data curation, formal analysis; M.M.A.: writing - review and editing, data curation, formal analysis, graphical illustrations; S.B.: writingreview and editing, data curation, formal analysis; G.A.P.G.: writing-review and editing, data curation, formal analysis; L.A.: writing—review and editing, formal analysis; M.V.: writing-review and editing, formal analysis; A.P.D.C.: writing-review and editing; P.S.P.A.: writing-review and editing; M.A.B.S.: formal analysis; M.K.: writing—review and editing; E.N.B.: writing-review and editing; R.V.L.: writing—review and editing; W.D.: writing—review and editing; S.d.-M.: writingreview and editing, formal analysis; A.C.: writing-review and editing, formal analysis. All authors have read and agreed to the published version of the manuscript.

Funding: This research received no external funding.

Acknowledgments: The authors are grateful to the volunteers recruited by Morobe Development Foundation (Papua New Guinea) through the UNV program, DroneSeed staff, Ministry of Forestry Fiji, as well as to the following people for their contribution with graphical illustration support, and reviewing and/or editing the draft versions of the manuscript: Anna Kvashuk, Jonanthan Aquino, Silvia Pizzigoni, Chima Iheaturu, Nivedhitha Ajithkumar, Bharadwaj Vangipuram, Stefano Puliti and Tiffani Manteuffel-Ross. The authors would also like to thank three anonymous reviewers for their critical feedback, which helped improve the quality and applicability of the manuscript.

Conflicts of Interest: The authors declare that they have no conflict of interest.

\section{References}

Note: References 4, 5, 11, 13, 14, 16, 35, 36, 37, 38, 39, 40, 41, 42, 43, 44, 45, 46, 47, 48, 49, 50, 51, 52, 53, 54, 55, 60, 61, 62, $76,77,78,79,83,84,85,88,89,90,91,92,93,94,95,96,98,99,100,101,102,103,104,106,107,108,109,110,111,112,113$, $115,116,117,118,119,120,122,123,124,125,127,128,129,130,131,132,133,134,139,140,142,143,145,146,147,148$, $149,150,151,152,153,154,155,156,159,160,162,163,165,167,168,169,170,171,172,175,178,180,181,182,183,190$, $191,192,193,194,198,199,200,206,207,210,213,218,219,220,221,223,224,225,226,227,228,230,232,233,234,235$, 236, 237, 238, 239 are non-peer-reviewed articles.

1. Reyer, C.; Guericke, M.; Ibisch, P.L. Climate change mitigation via afforestation, reforestation and deforestation avoidance: And what about adaptation to environmental change? New For. 2009, 38, 15-34. [CrossRef]

2. Bustamante, M.M.; Silva, J.S.; Scariot, A.; Sampaio, A.B.; Mascia, D.L.; Garcia, E.; Sano, E.; Fernandes, G.W.; Durigan, G.; Roitman, I.; et al. Ecological restoration as a strategy for mitigating and adapting to climate change: Lessons and challenges from Brazil. Mitig. Adapt. Strateg. Glob. Chang. 2019, 24, 1249. [CrossRef] 
3. UNFCCC. Land Use, Land Use Change and Forestry (LULUCF). United Nations Climate Change. 2021. Available online: https://unfccc.int/topics/land-use/workstreams/land-use--land-use-change-and-forestry-lulucf (accessed on 28 March 2021).

4. Elliot, S.D.; Gale, G.; Tiansawat, P. Abstracts-Day 3 I Kew. Royal Botanical Gardens (KEW). 2021. Available online: https://www. kew.org/science/engage/get-involved/conferences/reforestation-biodiversity-carbon-capture-livelihoods/day-3/abstracts (accessed on 7 April 2021).

5. Coldewey, D. That Night, a Forest Flew. TechCrunch. 2018. Available online: https://social.techcrunch.com/2018/11/26/thatnight-a-forest-flew-droneseed-is-planting-trees-from-the-air/ (accessed on 8 April 2021).

6. Crowther, T.W.; Glick, H.B.; Covey, K.R.; Bettigole, C.; Maynard, D.S.; Thomas, S.M.; Smith, J.R.; Hintler, G.; Duguid, M.C.; Amatulli, G. Mapping tree density at a global scale. Nature 2015, 525, 201-205. [CrossRef] [PubMed]

7. Brancalion, P.H.; Broadbent, E.N.; de-Miguel, S.; Cardil, A.; Rosa, M.R.; Almeida, C.T.; Almeida, D.R.; Chakravarty, S.; Zhou, M.; Gamarra, J.G. Emerging threats linking tropical deforestation and the COVID-19 pandemic. Perspect. Ecol. Conserv. 2020, 18, 243-246. [CrossRef]

8. Bloomfield, L.S.; McIntosh, T.L.; Lambin, E.F. Habitat fragmentation, livelihood behaviors, and contact between people and nonhuman primates in Africa. Landsc. Ecol. 2020, 35, 985-1000. [CrossRef]

9. UN/DESA Policy Brief \#80: Forests at the Heart of a Green Recovery from the COVID-19 Pandemic/United Nations Department of Economic and Social Affairs. 2020. Available online: https://www.un.org/development/desa/dpad/publication/un-desapolicy-brief-80-forests-at-the-heart-of-a-green-recovery-from-the-covid-19-pandemic/ (accessed on 18 June 2021).

10. Mohan, M.; Rue, H.A.; Bajaj, S.; Galgamuwa, G.P.; Adrah, E.; Aghai, M.M.; Broadbent, E.N.; Khadamkar, O.; Sasmito, S.D.; Roise, J. Afforestation, reforestation and new challenges from COVID-19: Thirty-three recommendations to support Civil Society Organizations (CSOs). J. Environ. Manag. 2021, 112277. [CrossRef]

11. Deforestation and Forest Degradation, International Union for Conservation of Nature. 2021. Available online: https://www. iucn.org/resources/issues-briefs/deforestation-and-forest-degradation (accessed on 18 June 2021).

12. Elliott, S. The potential for automating assisted natural regeneration of tropical forest ecosystems. Biotropica 2016, 48, 825-833. [CrossRef]

13. Stelzer, H. How to plant forest tree seedlings. Extension: University of Missouri, g5008. University of Missouri Extension. 2019. Available online: https: / extension.missouri.edu/publications/g5008 (accessed on 12 March 2021).

14. Oregon Forest Resources Institute, Reforestation after harvest. 2018. Available online: https://oregonforests.org/sites/default/ files/2018-02/04_Reforestation-after-harvest.pdf (accessed on 31 March 2020).

15. Haigh, M.J. Connective practices in sustainability education. J. Appl. Tech. Educ. Sci. 2017, 7, 6-30. [CrossRef]

16. Samurovic, K. Mega Tree Planting Efforts Around the World. Geographyrealm 2020. Available online: https://www. geographyrealm.com/mega-tree-planting-efforts-around-the-world/ (accessed on 28 March 2021).

17. Brancalion, P.H.S.; Viani, R.A.; Strassburg, B.B.N.; Rodrigues, R.R. Finding the money for tropical forest restoration. Unasylva 2012, 63, 25-34.

18. Banks-Leite, C.; Pardini, R.; Tambosi, L.R.; Pearse, W.D.; Bueno, A.A.; Bruscagin, R.T.; Condez, T.H.; Dixo, M.; Igari, A.T.; Martensen, A.C. Using ecological thresholds to evaluate the costs and benefits of set-asides in a biodiversity hotspot. Science 2014, 345, 1041-1045. [CrossRef]

19. Chazdon, R.L.; Guariguata, M.R. Natural regeneration as a tool for large-scale forest restoration in the tropics: Prospects and challenges. Biotropica 2016, 48, 716-730. [CrossRef]

20. Fargione, J.; Haase, D.L.; Burney, O.T.; Kildisheva, O.A.; Edge, G.; Cook-Patton, S.C.; Chapman, T.; Rempel, A.; Hurteau, M.D.; Davis, K.T. Challenges to the reforestation pipeline in the United States. Front. For. Glob. Chang. 2021, 4, 8. [CrossRef]

21. Fox, J.M.; Yokying, P.; Paudel, N.S.; Chhetri, R. Another Possible Cost of COVID-19: Returning Workers May Lead to Deforestation in Nepal. Scholar Space. 2020. Available online: http:/ / hdl.handle.net/10125/69942 (accessed on 21 January 2021).

22. Chu, A.M.; Tsang, J.T.; Chan, J.N.; Tiwari, A.; So, M.K. Analysis of travel restrictions for COVID-19 control in Latin America through network connectedness. J. Travel Med. 2020, 27, taaa176. [CrossRef]

23. Haghani, M.; Bliemer, M.C.; Goerlandt, F.; Li, J. The scientific literature on coronaviruses, COVID-19 and its associated safetyrelated research dimensions: A scientometric analysis and scoping review. Saf. Sci. 2020, 129, 104806. [CrossRef]

24. Masarei, M.; Guzzomi, A.L.; Merritt, D.J.; Erickson, T.E. Factoring restoration practitioner perceptions into future design of mechanical direct seeders for native seeds. Restor. Ecol. 2019, 27, 1251-1262. [CrossRef]

25. Grossnickle, S.C.; Ivetić, V. Direct seeding in reforestation-A field performance review. Reforesta 2017, 4, 94-142. [CrossRef]

26. Commander, L.E.; Rokich, D.P.; Renton, M.; Dixon, K.W.; Merritt, D.J. Optimizing seed broadcasting and green stock planting for restoration in the Australian arid zone. J. Arid Environ. 2013, 88, 226-235. [CrossRef]

27. Merritt, D.J.; Dixon, K.W. Restoration seed banks-A matter of scale. Science 2011, 332, 424-425. [CrossRef]

28. Vovchenko, N.; Novikov, A.; Sokolov, S.; Tishchenko, E. A proposed technology to ensure high-precision aerial seeding of certified seeds. In IOP Conference Series: Earth and Environmental Science; IOP Publishing: Voronezh, Russia, 2020. [CrossRef]

29. Larson, J.E.; Hallman, R. Equipment for Reforestation and Timber Stand Improvement; Forest Service, Equipment Development Center: Missoula, MT, USA, 1980.

30. Becker, R. Effective Aerial Reseeding Methods: Market Search Report; Gen. Tech. Rep. 01511204-SDTDC; USDA Forest Service, San Dimas Technology and Development Center: San Dimas, CA, USA, 2001; p. 19. Available online: https://www.fs.fed.us/t-d/ pubs / pdf/01511204.pdf (accessed on 18 February 2021). 
31. Andrio, A. Development of UAV technology in seed dropping for aerial revegetation practices in Indonesia. IOP Conf. Ser. Earth Environ. Sci. 2019, 308, 012051. [CrossRef]

32. Buters, T.; Belton, D.; Cross, A. Seed and seedling detection using unmanned aerial vehicles and automated image classification in the monitoring of ecological recovery. Drones 2019, 3, 53. [CrossRef]

33. Aghai, M.; Manteuffel-Ross, T. Enhanced direct seeding efforts with unmanned aerial vehicle (UAV) "swarms" and seed technology. Tree Plant. Notes 2020, 63, 32-48.

34. Shannon, D.P.; Elliott, S. Developing Aerial Seeding by UAVs: Lessons from Direct Seeding. In Automated Forest Restoration FORRU-CMU. 2020, pp. 75-83. Available online: https://www.forru.org/sites/default/files/public/publications/resources / forru-0000099-0023-en.pdf (accessed on 12 January 2021).

35. Peters, A. These Tree-Planting Drones are Firing Seed Missiles to Restore the World's Forests. Fast Company. 2019. Available online: https: / www.fastcompany.com/90329982/these-tree-planting-drones-are-firing-seed-missiles-to-restore-the-worldsforests (accessed on 29 March 2021).

36. Clarke, K. Mangrove-Planting Drones Set to Swoop in to Restore UAE Coastline. 2020. Available online: https://www. thenationalnews.com/uae/environment/mangrove-planting-drones-set-to-swoop-in-to-restore-uae-coastline-1.984279 (accessed on 29 March 2021).

37. Brewis, H. Tree-Planting Drones Could Help Restore World's Forests. 2019. Available online: https://www.standard.co.uk/ news/world/treeplanting-drones-could-help-restore-world-s-forests-a4116376.html (accessed on 2 April 2021).

38. Tarantola, A. Dendra System's seed-spitting drones rebuild forests from the air. Engadget 2020. Available online: https: / / www.engadget.com/dendra-systems-seedspitting-drones-rebuild-forests-from-the-air-170048595.html (accessed on 8 April 2021).

39. Iyengar, R. This Company is Using Drones to Replant Forests Devastated by Wildfires. 2020. Available online: https:/ /www.cnn. com/2020/12/03/tech/droneseed-wildfire-california-oregon/index.html (accessed on 29 March 2021).

40. Flash Forest 'Kickstart'. Flash Forest: Using Drones to Plant 1 Billion Trees. Kickstarter. 2021. Available online: https: / / www.kickstarter.com/projects/499734388/flash-forest-using-drones-to-plant-1-billion-trees-by- (accessed on 29 March 2021).

41. Dji News. Drones for Good: Planting Seeds from the Sky. DJI Official. 2018. Available online: https://www.dji.com/ca/altitude/ drones-for-good-planting-seeds-co2-revolution (accessed on 29 March 2021).

42. Stone, E. Drones Spray Tree Seeds from the Sky to Fight Deforestation. National Geographic. 2017. Available online: http:/ /media. muckrack.com.s3.amazonaws.com/portfolio/items/1585724/Drones_Spray_Tree_Seeds_From_the_Sky_to_Fight_Defo.pdf (accessed on 30 March 2021).

43. Frandino, N. Drones Plant Trees from the Sky after U.S. wildfires. Reuters 2020. Available online: https://www.reuters.com/ article/us-usa-wildfires-droneseed-idUSKBN28B5J3 (accessed on 2 April 2021).

44. Meigs, C.; Chaplin, D. Reforestation Pilot Project with Seed Pucks in British Columbia. One Tree Planted. 2021. Available online: https:/ / onetreeplanted.org/blogs/stories/reforestation-droneseed-pilot (accessed on 3 April 2021).

45. Rivers of Carbon. Stone Age to 'Drone Age'-Using Technology for Reforestation. Rivers of Carbon. 2018. Available online: https:/ / riversofcarbon.org.au/stone-age-drone-age-using-technology-reforestation/ (accessed on 5 April 2021).

46. CBC News. Seed for Speed: Drones could be Game-Changer for Forestry. 2018. Available online: https://www.cbc.ca/news / canada/edmonton/seed-for-speed-drones-could-be-game-changer-for-forestry-1.4675334 (accessed on 8 April 2021).

47. Madan, S. Drone Reforestation: How New Tech is Rehabilitating Forests. BORGEN. 2021. Available online: https://www. borgenmagazine.com/drone-reforestation/ (accessed on 8 April 2021).

48. XAG. XAG Deploys Drones to Seed Burned Land for Australian Fire Recovery. Cision PR Newswire. 2020. Available online: https:/ / www.prnewswire.com/news-releases/xag-deploys-drones-to-seed-burned-land-for-australian-fire-recovery-30 1058231.html (accessed on 8 April 2021).

49. Benzaken, H. These Drones Can Plant 100,000 New Trees per Day. Goodnet. 2018. Available online: https://www.goodnet.org/ articles/these-drones-plant-100000-new-trees-per-day (accessed on 10 April 2021).

50. Haziq, S. UAE: Drones Plant 10,000 Ghaf Trees within Hours-News. Khaleej Times-News. 2021. Available online: https: //www.khaleejtimes.com/news/uae-drones-plant-10000-ghaf-trees-within-hours (accessed on 1 April 2021).

51. Das, M. How IISc Scientists Are Seed Bombing a Barren Land in Karnataka Using Drones. The News Minute. 2017. Available online: https: / / www.thenewsminute.com/article/how-iisc-scientists-are-seed-bombing-barren-land-karnataka-using-drones64155 (accessed on 29 March 2020).

52. Changestarted. Touch the Sky to Plant Trees-Yes, There Are Companies Using DRONES to Plant Trees. 2020. Available online: https: / / changestarted.com/touch-the-sky-to-plant-trees-yes-there-are-companies-using-drones-to-plant-trees / (accessed on 1 April 2021).

53. The National. Abu Dhabi Uses Drones to Lay Seeds in Mangrove Regeneration Plan. The National. 2020. Available online: https:/ / www.thenationalnews.com/uae/environment/abu-dhabi-uses-drones-to-lay-seeds-in-mangrove-regenerationplan-1.1112512 (accessed on 8 April 2021).

54. Telangana Today. Telangana to Use Drone and AI Driven Forest Restoration. Telangana Today. 2020. Available online: https: / telanganatoday.com/trees-from-sky-telangana-to-use-drone-and-ai-driven-forest-restoration (accessed on 8 April 2021).

55. Our Bureau. Marut Drontech to Identify, Collect Native Tree Seeds. 2021. Available online: https://www.thehindubusinessline. com/economy/marut-drontech-to-identify-collect-native-tree-seeds/article33926517.ece (accessed on 10 April 2021). 
56. Imangholiloo, M.; Saarinen, N.; Markelin, L.; Rosnell, T.; Näsi, R.; Hakala, T.; Honkavaara, E.; Holopainen, M.; Hyyppä, J.; Vastaranta, M. Characterizing seedling stands using leaf-off and leaf-on photogrammetric point clouds and hyperspectral imagery acquired from unmanned aerial vehicle. Forests 2019, 10, 415. [CrossRef]

57. Mohan, M.; Silva, C.A.; Klauberg, C.; Jat, P.; Catts, G.; Cardil, A.; Hudak, A.T.; Dia, M. Individual tree detection from unmanned aerial vehicle (UAV) derived canopy height model in an open canopy mixed conifer forest. Forests 2017, 8, 340. [CrossRef]

58. Mlambo, R.; Woodhouse, I.H.; Gerard, F.; Anderson, K. Structure from motion (SfM) photogrammetry with drone data: A low cost method for monitoring greenhouse gas emissions from forests in developing countries. Forests 2017, 8, 68. [CrossRef]

59. Iglhaut, J.; Cabo, C.; Puliti, S.; Piermattei, L.; O'Connor, J.; Rosette, J. Structure from motion photogrammetry in forestry: A review. Curr. For. Rep. 2019, 5, 155-168. [CrossRef]

60. Daly, J. Re-Planting a Forest, One Drone at a Time. Wired. 2015. Available online: https://www.wired.com/brandlab/2015/07/ re-planting-forest-one-drone-time/ (accessed on 2 April 2021).

61. Kaufman, R. Seeding Trees on the Fly. Inside Unmanned Systems. 2016. Available online: https://insideunmannedsystems.com/ seeding-trees-fly/ (accessed on 8 April 2021).

62. Foresttech. Aerial Tree Planting Systems Being Showcased. ForestTECH. 2020. Available online: https://foresttech.events/aerialtree-planting-systems-being-showcased/ (accessed on 8 April 2021).

63. Fromm, M.; Schubert, M.; Castilla, G.; Linke, J.; McDermid, G. Automated detection of conifer seedlings in drone imagery using convolutional neural networks. Remote Sens. 2019, 11, 2585. [CrossRef]

64. Puliti, S.; Granhus, A. Drone Data for decision making in regeneration forests: From raw data to actionable insights. J. Unmanned Veh. Syst. 2020, 9. [CrossRef]

65. Puliti, S.; Solberg, S.; Granhus, A. Use of UAV photogrammetric data for estimation of biophysical properties in forest stands under regeneration. Remote Sens. 2019, 11, 233. [CrossRef]

66. Spoorthi, S.; Shadaksharappa, B.; Suraj, S.; Manasa, V.K. Freyr drone: Pesticide/fertilizers spraying drone-an agricultural approach. In Proceedings of the 2017 2nd International Conference on Computing and Communications Technologies (ICCCT), Chennai, India, 23-24 February 2017; pp. 252-255.

67. Mogili, U.R.; Deepak, B.B.V.L. Review on application of drone systems in precision agriculture. Procedia Comput. Sci. 2018, 133, 502-509. [CrossRef]

68. Wang, L.; Lan, Y.; Zhang, Y.; Zhang, H.; Tahir, M.N.; Ou, S.; Liu, X.; Chen, P. Applications and prospects of agricultural unmanned aerial vehicle obstacle avoidance technology in China. Sensors 2019, 19, 642. [CrossRef]

69. Dalla Corte, A.P.; Rex, F.E.; Almeida, D.R.A.; Sanquetta, C.R.; Silva, C.A.; Moura, M.M.; Wilkinson, B.; Zambrano, A.M.A.; Cunha Neto, E.M.; Veras, H.F. Measuring individual tree diameter and height using GatorEye High-Density UAV-Lidar in an integrated crop-livestock-forest system. Remote Sens. 2020, 12, 863. [CrossRef]

70. Dalla Corte, A.P.; Souza, D.V.; Rex, F.E.; Sanquetta, C.R.; Mohan, M.; Silva, C.A.; Zambrano, A.M.A.; Prata, G.; de Almeida, D.R.A.; Trautenmüller, J.W. Forest inventory with high-density UAV-Lidar: Machine learning approaches for predicting individual tree attributes. Comput. Electron. Agric. 2020, 179, 105815. [CrossRef]

71. Kachamba, D.J.; Ørka, H.O.; Gobakken, T.; Eid, T.; Mwase, W. Biomass estimation using 3D data from unmanned aerial vehicle imagery in a tropical woodland. Remote Sens. 2016, 8, 968. [CrossRef]

72. Nezami, S.; Khoramshahi, E.; Nevalainen, O.; Pölönen, I.; Honkavaara, E. Tree species classification of drone hyperspectral and RGB imagery with deep learning convolutional neural networks. Remote Sens. 2020, 12, 1070. [CrossRef]

73. Krenz, J.; Greenwood, P.; Kuhn, N.J. Soil degradation mapping in drylands using Unmanned Aerial Vehicle (UAV) data. Soil Syst. 2019, 3, 33. [CrossRef]

74. Rossi, F.C.; Fritz, A.; Becker, G. Combining satellite and UAV imagery to delineate forest cover and basal area after mixed-severity fires. Sustainability 2018, 10, 2227. [CrossRef]

75. Dainelli, R.; Toscano, P.; Di Gennaro, S.F.; Matese, A. Recent Advances in Unmanned Aerial Vehicles Forest Remote Sensing-A Systematic Review. Part II: Research Applications. Forests 2021, 12, 397. [CrossRef]

76. Nixon, A. DroneSeed. Is Planting Trees from the Air. Best Drone for the Job. 2018. Available online: https://bestdroneforthejob. $\mathrm{com} / \mathrm{blog} /$ droneseed-trees-air/ (accessed on 7 April 2021).

77. DroneSeed (Ballard Brewery District, Seattle, WA, USA). Personal communication, 2021.

78. WWF. Exploring Tree-Planting Drones to Make Australia Green Again! World Wildlife Fund-Blog. 2020. Available online: https://www.wwf.org.au/news/blogs/exploring-tree-planting-drones-to-make-australia-green-again (accessed on 8 April 2021).

79. Brunell, D.C. Drones Planting Trees in Burned Wildlands. Auburn Reporter. 2019. Available online: https://www.auburnreporter.com/opinion/drones-planting-trees-in-burned-wildlands/ (accessed on 2 April 2021).

80. Pearson, D.E.; Valliant, M.; Carlson, C.; Thelen, G.C.; Ortega, Y.K.; Orrock, J.L.; Madsen, M.D. Spicing up restoration: Can chili peppers improve restoration seeding by reducing seed predation? Restor. Ecol. 2019, 27, 254-260. [CrossRef]

81. Porter, S.S. Adaptive divergence in seed color camouflage in contrasting soil environments. New Phytol. 2013, 197, 1311-1320. [CrossRef]

82. Taylor, J.B.; Cass, K.L.; Armond, D.N.; Madsen, M.D.; Pearson, D.E.; St. Clair, S.B. Deterring rodent seed-predation using seed-coating technologies. Restor. Ecol. 2020, 28, 927-936. [CrossRef] 
83. Reforestation Methods Reforestation Projects, Reforestation.Me. 2012. Available online: https://reforestation.me/reforestationmethods / (accessed on 6 April 2021).

84. Airseed Technologies. 2020. Available online: https:/ / airseedtech.com/ (accessed on 20 March 2021).

85. Peters, A. These drones will PLANT 40,000 Trees in a MONTH. BY 2028 2020, They'll Have PLANTED 1 Billion. 2020. Available online: https:/ / www.fastcompany.com/90504789/these-drones-can-plant-40000-trees-in-a-month-by-2028-theyll-have-planted1-billion (accessed on 20 March 2021).

86. Petritoli, E.; Leccese, F.; Ciani, L. Reliability and maintenance analysis of unmanned aerial vehicles. Sensors $2018,18,3171$. [CrossRef]

87. Kurkute, S.R.; Deore, B.D.; Kasar, P.; Bhamare, M.; Sahane, M. Drones for smart agriculture: A technical report. Int. J. Res. Appl. Sci. Eng. Technol. 2018, 6, 341-346. [CrossRef]

88. Bullfrog Power, Flash Forest: Revolutionizing Reforestation with Tree-Planting Drones. Bullfrog Power. 2020. Available online: https://www.bullfrogpower.com/blog-flash-forest-revolutionizing-reforestation-tree-planting-drones/ (accessed on 8 April 2021).

89. Whiting, K. This Tech Company Is Using AI and Drones to Plant Trees. World Economic Forum. 2019. Available online: https:/ / www.weforum.org/agenda/2019/12/technology-artificial-intelligence-ai-drone-trees-deforestation/ (accessed on 30 March 2021).

90. Purtill, J. Swarms of Seed-Planting 'Sky Tractors' May One Day Rewild the Planet. Australian Broadcasting Corporation. 2020. Available online: https:/ / www.abc.net.au/triplej/programs/hack/swarms-of-seed-planting-drones-may-one-day-rewild-theplanet/12782800 (accessed on 3 April 2021).

91. Quode Brisbane. Save the Planet with Drones and AI. QODE Brisbane Virtual. 2019. Available online: https:/ /qodebrisbane. com/save-the-planet-with-drones-and-ai/ (accessed on 7 April 2021).

92. Caboz, J. This South African Invention Allows Drones to Plant Hundreds of Trees in Minutes. BusinessInsider. 2019. Available online: https: / / www.businessinsider.co.za/ this-south-african-made-drone-can-help-re-plant-100-million-trees-a-year-from2023-2019-6 (accessed on 8 April 2021).

93. Nordquist, C. Drones the Latest Tool in Reforestation Efforts Following Wildfires. KMGH. 2021. Available online: https: //www.thedenverchannel.com/news/national/drones-the-latest-tool-in-reforestation-efforts-following-wildfires (accessed on 10 April 2021).

94. Herranz, A.G. Smartseeds and Drones Could Plant 10 Million Trees in Ten Years. Available online: https://en.reset.org/blog/ smart-seeds-and-drones-could-plant-10-million-trees-ten-years-09032019 (accessed on 8 April 2021).

95. $\mathrm{CO}_{2}$ Revolution 2019, Nuestra Revolución. $\mathrm{CO}_{2}$ Revolution. 2020. Available online: https://co2revolution.es/nuestrarevolucion/ (accessed on 5 April 2021).

96. DroneSeed. Available online: https://www.droneseed.com/ (accessed on 1 April 2021).

97. Novikov, A.I.; Ersson, B.T. Aerial seeding of forests in Russia: A selected literature analysis. In IOP Conference Series: Earth and Environmental Science; IOP Publishing: Voronezh, Russia, 2021; Volume 226, p. 012051. [CrossRef]

98. Manzer, J. Flash of inspiration-University of Victoria. 2020. Available online: https://www.uvic.ca/news/topics/2020+torchflash-of-inspiration+news (accessed on 5 April 2021).

99. Clugston, E. Drones, Seeds, \& Fires: How DroneSeed Plants Trees from the Sky. CleanTechnica. 2019. Available online: https:/ / cleantechnica.com/2019/02/08/drones-seeds-fires-how-droneseed-plants-trees-from-the-sky/ (accessed on 5 April 2021).

100. IFLScience. Former NASA Engineer Plans to Plant 1 Billion Trees a Year Using Drones. IFLScience. Available online: https: //www.iflscience.com/environment/drones-take-reforestation-new-heights/ (accessed on 8 April 2021).

101. Dukowitz, Z. AirSeed Technologies' Podder Lets Drones Plant Hundreds of Trees in Minutes. UAV Coach. 2019. Available online: https: / / uavcoach.com/airseed-technologies/ (accessed on 8 April 2021).

102. Hasco, L. One Startup Company's Goal-1 Billion Trees by 2028, All Planted by Drones. 2020. Available online: https://www. pennlive.com/nation-world/2020/08/one-startup-companys-goal-1-billion-trees-by-2028-all-planted-by-drones.html (accessed on 29 March 2021).

103. Amorós, L. (Dronecoria, Elche, Spain). Personal communication, 2021.

104. Solana, A. Drones, Data Analytics, Smart Seeds: How to Reforest 1000 Times Faster after Wildfires. ZDNet. 2018. Available online: https:/ / www.zdnet.com/article/drones-Data-analytics-smart-seeds-how-to-reforest-x1000-faster-after-wildfires / (accessed on 10 April 2021).

105. Hodges, A.N.; Kennedy, M.D. Physical exertion and working efficiency of reforestation workers. J. Occup. Med. Toxicol. 2011, 6, 1-7. [CrossRef]

106. Newton, M. AirSeed: Do Fleets of Drones Hold the Answer to Reforesting Australia's Devastated Outback? 2020. Available online: https:/ / en.reset.org/blog/airseed-do-fleets-drones-hold-answer-reforesting-australias-devastated-outback-02122020 (accessed on 1 April 2021).

107. Sengupta, T. Drones Plant Trees from Sky to Speed up Wildfire Reforestation in US. Hindustan Times. 2020. Available online: https: / / www.hindustantimes.com/it-s-viral/drones-plant-seeds-from-the-sky-in-land-damaged-in-wildfires-in-usto-help-speed-up-reforestation/story-A2xnuFvKfoiAwoOIcFlYfI.html (accessed on 3 April 2021). 
108. European Commission. Rapid Tree-Planting through the Use of Remote Sensing and Unmanned Vehicle Planting Technologies for Large Scale Reforestation. Available online: https:/ / cordis.europa.eu/project/id/711392 (accessed on 2 April 2021).

109. Seedballs Kenya. Seedballs Kenya. Available online: http://www.seedballskenya.com/seedballs/4593024001 (accessed on 7 April 2021).

110. DTE Staff, Can Drones Replace Humans in Reforestation Tasks? Down to Earth. 2016. Available online: https://www. downtoearth.org.in/news/forests/can-drones-replace-humans-in-reforestation-efforts--54710 (accessed on 5 April 2021).

111. Gabbert, B. Replanting a Burned Forest with a Swarm of Drones. 2018. Wildfire Today. Available online: https://wildfiretoday. com/2018/11/27/replanting-a-burned-forest-with-a-swarm-of-drones/ (accessed on 2 April 2021).

112. Shvedsky, L. These tree-planting drones are firing 'seed missiles' into the ground. Less than a year later, they're already 20 inches tall. GOOD. 2019. Available online: https:/ / www.good.is/articles/drones-planting-trees (accessed on 8 April 2021).

113. Bold Business, Tree planting drones might rescue the planet. Bold Business. 2018. Available online: https://www.boldbusiness. $\mathrm{com} /$ transportation/tree-planting-drones/ (accessed on 8 April 2021).

114. Hsu, A.J.; Pruckner, S.; Satterthwaite, E.V.; Weatherdon, L.V.; Hadley, K.; Nguyen, E.T.T. Challenges and Recommendations for Equitable Use of Aerial Tools for Mangrove Research. Front. Mar. Sci. 2021, 8, 277. [CrossRef]

115. Chanthadavong, A. AirSeed Technologies' Mission to Give Mother Nature a 'Kick up the Bum'. 2020. Available online: https:/ / www.zdnet.com/article/airseed-technologies-mission-to-help-reforestation-in-bushfire-devastated-regions / (accessed on 1 April 2021).

116. Thomsen, S. A Startup Hoping to Plant 1 Million Trees a Year by Drone just Raised $\$ 437,000$ from Crowdfunding. Startup Daily. 2020. Available online: https:/ / www.startupdaily.net/2020/03/a-startup-hoping-to-plant-1-million-trees-a-year-by-dronejust-raised-437000-from-crowdfunding/ (accessed on 30 March 2021).

117. Manulife, Using Drones to Replant Forests. Corporate. 2021. Available online: https://www.manulife.com/en/about/ sustainability/using-drones-to-replant-forests.html (accessed on 3 April 2021).

118. FlashForest. Pilot Projects-Fall 2020 and Spring Flash Forest. 2021. Available online: https://flashforest.ca/blog/pilot-projectsfall-2020-and-spring-2021 (accessed on 29 March 2021).

119. Penton, K. Reforesting in a Flash. Okanagan Edge. 2019. Available online: https://okanaganedge.net/2019/12/09/reforestingin-a-flash/ (accessed on 5 April 2021).

120. Reuters. Drones to Drop Seeds to Boost Koala Gum Tree Numbers. CNN. 2020. Available online: https://www.cnn.com/2020/1 0/20/asia/drones-gum-trees-australia-scli-intl/index.htm (accessed on 8 April 2021).

121. Samiappan, S.; Hathcock, L.; Turnage, G.; McCraine, C.; Pitchford, J.; Moorhead, R. Remote sensing of wildfire using a small unmanned aerial system: Post-fire mapping, vegetation recovery and damage analysis in Grand Bay, Mississippi/Alabama, USA. Drones 2019, 3, 43. [CrossRef]

122. Baker, E. Case Study: Providing Data Insights Critical to Ecosystem Restoration on LHI. Dendra Systems Blog. 2021. Available online: https:/ / blog.dendra.io/ case-study-ecosystem-restoration-lhi (accessed on 6 April 2021).

123. Gray, D.D. Thai Team Fights Climate Change with Aerial Reseeding-Nikkei Asia. Nikkei Asia. 2017. Available online: https: / / asia.nikkei.com/Life-Arts/Life/Thai-team-fights-climate-change-with-aerial-reseeding2 (accessed on 8 April 2021).

124. Sapra, B. Dubai's Cafu Pilots Seed-Spitting Drones to Turn Desert Green. WIRED Middle East. 2021. Available online: http:/ / wired.me/science/environment/cafu-deploys-seed-spitting-drones-ghaf-tree/ (accessed on 8 April 2021).

125. Callaghan, G. Can Swarms of seed-Bearing Drones Help Regrow the Planet's Forests? The Sydney Morning Herald. 2017. Available online: https:/ / www.smh.com.au/lifestyle/can-swarms-of-seedbearing-drones-help-regrow-the-planets-forests-20 170823-gy2ei5.html (accessed on 8 April 2021).

126. Şahin, M.; Yıldırım, M.T. Application of a Fixed-Wing Unmanned Aerial Vehicle (UAV) in Reforestation of Lebanon Cedar (Cedrus Libani, A. Rich). 2011. Available online: http:/ / aiac.ae.metu.edu.tr/paper.php?No=AIAC-2011-073 (accessed on 14 January 2021).

127. Ministry for Primary Industries, One Billion Trees Programme Science Projects. Ministry for Primary Industries—New Zealand Government. 2020. Available online: https://www.mpi.govt.nz/forestry/funding-tree-planting-research/one-billion-treesprogramme/science-and-the-one-billion-trees-programme/one-billion-trees-programme-science-projects/ (accessed on 10 April 2021).

128. TheCivilEngineer.org, Planting Trees Using Drones is Being Tested in India. 2017. Available online: https:/ /www.thecivilengineer. org/news-center/latest-news/item/1388-planting-trees-using-drones-is-being-tested-in-india (accessed on 30 March 2021).

129. The Times of India. In a First in State, 10,000 seed Balls Dropped from Drone in Udaipur. The Times of India. 2020. Available online: https: / / timesofindia.indiatimes.com/city/udaipur/in-a-first-in-state-10k-seed-balls-dropped-from-drone-in-udaipur/ articleshow /77513607.cms (accessed on 8 April 2021).

130. CISION PR Newswire. First-of-their-kind Drone Swarms to Restore Oregon Rangelands. 2019. Available online: https://www. prnewswire.com/news-releases / first-of-their-kind-drone-swarms-to-restore-oregon-rangelands-300799025.html (accessed on 1 April 2021).

131. Foresttech. Drone Swarms for Tree Planting and Spraying Operations. ForestTECH. 2019. Available online: https://foresttech. events / drone-swarms-for-tree-planting-and-spraying-operations/ (accessed on 10 April 2021).

132. Pix4D. A Tree Planting Drone to Re-Green the World. 2020. Available online: https://www.pix4d.com/blog/tree-planting-drone (accessed on 20 March 2021). 
133. Peters, A. These Tree-Planting Drones are about to Start an Entire Forest from the Sky. Fast Company. 2017. Available online: https: / / www.fastcompany.com/40450262/these-tree-planting-drones-are-about-to-fire-a-million-seeds-to-re-grow-a-forest (accessed on 29 March 2021).

134. Peters, A. This Startup Lets you Subscribe to Support an Army of Drones that's Planting Millions of Trees. 2019. Available online: https:/ / www.fastcompany.com/90405143/this-startup-lets-you-subscribe-to-support-an-army-of-drones-thatsplanting-millions-of-trees (accessed on 29 March 2021).

135. Jalonen, R.; Valette, M.; Boshier, D.; Duminil, J.; Thomas, E. Forest and Landscape Restoration Severely Constrained by a Lack of Attention to the Quantity and Quality of Tree Seed: Insights from a global survey. Conserv. Lett. 2018, 11, e12424. [CrossRef]

136. White, A.; Fant, J.B.; Havens, K.; Skinner, M.; Kramer, A.T. Restoring species diversity: Assessing capacity in the US native plant industry. Restor. Ecol. 2018, 4, 605-611. [CrossRef]

137. Anderegg, W.R.; Konings, A.G.; Trugman, A.T.; Yu, K.; Bowling, D.R.; Gabbitas, R.; Karp, D.S.; Pacala, S.; Sperry, J.S.; Sulman, B.N. Hydraulic diversity of forests regulates ecosystem resilience during drought. Nature 2018, 561, 538-541. [CrossRef] [PubMed]

138. Johnson, D.J.; Magee, L.; Pandit, K.; Bourdon, J.; Broadbent, E.N.; Glenn, K.; Kaddoura, Y.; Machado, S.; Nieves, J.; Wilkinson, B.E. Canopy tree density and species influence tree regeneration patterns and woody species diversity in a longleaf pine forest. Forest Ecol. Manag. 2021, 490, 119082. [CrossRef]

139. ClimaCell. Why Drone Can't Use Regular Weather Forecasts. 2018. Available online: https://www.tomorrow.io/blog/whydrones-cant-use-regular-weather-forecasts / (accessed on 29 March 2021).

140. Singhal, G.; Bansod, B.; Mathew, L. Unmanned Aerial Vehicle Classification, Applications and Challenges: A Review. Preprints 2018. [CrossRef]

141. Boucher, D.; Gauthier, S.; Thiffault, N.; Marchand, W.; Girardin, M.; Urli, M. How climate change might affect tree regeneration following fire at northern latitudes: A review. New For. 2020, 51, 543-571. [CrossRef]

142. Roberts, T. Manufacturing a Fleet of Drones to Scale Reforestation. 3D Hubs. Available online: https://www.3dhubs.com/blog/ how-to-manufacture-a-fleet-of-drones-and-save-the-forest/ (accessed on 5 April 2021).

143. Tiansawat, P.; Elliott, S. Unmanned Aerial Vehicles for Automated Forest Restoration. 2020. Available online: https://www.forru. org/sites/default/files/public/publications/resources/forru-0000099-0028-en.pd (accessed on 2 April 2021).

144. Rani, A.L.K.A.; Chaudhary, A.M.R.E.S.H.; Sinha, N.; Mohanty, M.; Chaudhary, R. Drone: The green technology for future agriculture. Harit Dhara 2019, 2, 3-6.

145. Qin, Z.; Wang, W.; Dammer, K.H.; Guo, L.; Cao, Z. A real-time low-cost artificial intelligence system for autonomous spraying in palm plantations. arXiv 2021, arXiv:2103.04132.

146. Conca, J. Drones Can Reforest the Planet Faster than Humans Can. 2020. Available online: https://www.forbes.com/sites/ jamesconca/2020/09/30/drones-can-reforest-the-planet-faster-than-humans-can/ (accessed on 2 April 2021).

147. CBS Sacramento. Drones Being Used to Replant Forests Damaged by Wildfires. 2020. Available online: https://sacramento. cbslocal.com/2020/12/03/drones-replant-forests-wildfires/ (accessed on 2 April 2021).

148. Dukowitz, Z. DroneSeed Gets Approval to Fly BVLOS in 6 States for Reforestation Work. UAV Coach. 2020. Available online: https:/ / uavcoach.com/droneseed-bvlos/ (accessed on 1 April 2021).

149. Ball, M. Drone-Based Reseeding Service Gains BVLOS Approval. ARPAS-UK: The UK Drone Association/Unmanned Systems Technology. 2019. Available online: http:/ / www.arpas.uk/tag/drone-seed-planting/ (accessed on 2 April 2021).

150. Ikoba, J.J. US Company Deploys Drones to Replant Forests Devastated by Wildfires. Gizmochina. 2020. Available online: https: / / www.gizmochina.com/2020/12/04/us-company-deploys-drones-to-replant-forests-devastated-by-wildfires / (accessed on 8 April 2021).

151. Carey, T. Tree-Planting Drones Restore Charred Forests IFreethink. Freethink: Move the World. 2020. Available online: https:/ / www.freethink.com/articles/tree-planting-drones (accessed on 7 April 2021).

152. Drones in Site, Drones in Agriculture, Tree Planting Drones. DronesInsite. 2018. Available online: https://www.dronesinsite. com/drone-news/drones-in-agriculture/ (accessed on 10 April 2021).

153. Irish Tech News. Tree Planting Drone can plant 10000 Trees in One Day-ARPAS UK. 2020. Available online: http://www.arpas. uk/tree-planting-drone-can-plant-10000-trees-in-one-day/ (accessed on 29 March 2021).

154. Parks Canada Agency. Use of Unmanned Air Vehicle (UAV)/Drone-Banff National Park. 2019. Available online: https: //www.pc.gc.ca/en/pn-np/ab/banff/info/permis-permit/drone (accessed on 29 March 2021).

155. Barik, S. Privacy Fails to Take Off in India's New Drone Rules. 2021. Available online: https://entrackr.com/2021/03/privacyfails-to-take-off-in-indias-new-drone-rules/ (accessed on 18 March 2021).

156. Canadian Wildlife Federation. Canadian Wildlife Federation: Q. I Just Got a Drone and I Can't Wait to Start Shooting Pictures of Birds! Any Tips? 2021. Available online: https://cwf-fcf.org/en/about-cwf/faq/faqs/before-you-fly.html (accessed on 1 April 2021).

157. Mulero-Pázmány, M.; Jenni-Eiermann, S.; Strebel, N.; Sattler, T.; Negro, J.J.; Tablado, Z. Unmanned aircraft systems as a new source of disturbance for wildlife: A systematic review. PLoS ONE 2017, 12, e0178448. [CrossRef]

158. Rebolo-Ifrán, N.; Grilli, M.G.; Lambertucci, S.A. Drones as a threat to wildlife: YouTube complements science in providing evidence about their effect. Environ. Conserv. 2019, 46, 205-210. [CrossRef]

159. Reyes, M. Drones a Source of Disturbance for Wintering Water Birds. Courthouse News Service. 2020. Available online: https:/ / www.courthousenews.com/drones-a-source-of-disturbance-for-wintering-water-birds/ (accessed on 30 March 2021). 
160. Mayntz, M. Do Drones Threaten Birds or Help Them? The Spruce. 2020. Available online: https:/ /www.thespruce.com/birdsand-drones-3571688 (accessed on 29 March 2021).

161. Fraser, B.T.; Congalton, R.G. Issues in Unmanned Aerial Systems (UAS) data collection of complex forest environments. Remote Sens. 2018, 10, 908. [CrossRef]

162. Vander Jagt, B. How to Avoid Drowning in Drone Data. Commercial UAV News. 2016. Available online: https://www. commercialuavnews.com/energy/avoid-drowning-drone-data (accessed on 30 March 2021).

163. The Challenges of Drone Mapping. GIS Cloud. 2016. Available online: https://www.giscloud.com/blog/the-challenges-ofdrone-mapping/ (accessed on 18 June 2021).

164. Xiao, X.; Wei, X.; Liu, Y.; Ouyang, X.; Li, Q.; Ning, J. Aerial seeding: An effective forest restoration method in highly degraded forest landscapes of sub-tropic regions. Forests 2015, 6, 1748-1762. [CrossRef]

165. Brown, J. Can Drones Help to Save the Planet? Coverdrone Norway. 2018. Available online: https://www.coverdrone.com/no/ can-drones-help-to-save-the-planet/ (accessed on 8 April 2021).

166. Aleksandrowicz-Trzcińska, M.; Drozdowski, S.; Wołczyk, Z.; Bielak, K.; Żybura, H. Effects of reforestation and site preparation methods on early growth and survival of Scots Pine (Pinus sylvestris L.) in South-Eastern Poland. Forests 2017, 8, 421. [CrossRef]

167. Bower, M. The Future of Planting? Seeds from the Sky. The Sydney Morning Herald. 2020. Available online: https://www.smh. com.au/environment/conservation/the-future-of-planting-seeds-from-the-sky-20200208-p53yyz.html (accessed on 5 April 2021).

168. Razafison, R. Madagascar Experiments with Drones for its Massive Reforestation Effort. Mongabay Environmental News. 2020. Available online: https:/ /news.mongabay.com/2020/10/madagascar-experiments-with-drones-for-its-massive-reforestationeffort/ (accessed on 8 April 2021).

169. Ngounou, B. MADAGASCAR: Government to Acquire Ten Tree-Planting UAVs. Afrik 21. 2020. Available online: https: //www.afrik21.africa/en/madagascar-government-to-acquire-ten-tree-planting-uavs/ (accessed on 8 April 2021).

170. Dhankhar, L. Haryana Forest Dept Uses Drone to plant 5 lakh Seeds in Aravallis. Hindustan Times. 2020. Available online: https:/ / www.hindustantimes.com/gurugram/haryana-forest-dept-uses-drone-to-plant-5l-seeds-in-aravallis/story-83j7 5VA5ox3bhzNgAUp9OO.html (accessed on 5 April 2021).

171. Dayal, S. Aerial Seeding to Increase Green Cover in Aravallis. The Indian Express. 2020. Available online: https:/ /indianexpress. com/article/cities/delhi/aerial-seeding-to-increase-green-cover-in-aravallis-6530045/ (accessed on 5 April 2021).

172. Drishti IAS. Aerial Seeding in Haryana. Drishti IAS. 2020. Available online: https:/ /www.drishtiias.com/daily-updates/dailynews-analysis/aerial-seeding-in-haryana (accessed on 8 April 2021).

173. INCREDIBLE. "Powerful Seeds" Wins 1st Place Conservation Tech Prize for Reforestation Project. MedForest. 2021. Available online: https:/ / medforest.net/2021/01/29/powerful-seeds-by-dronecoria-wins-1st-place-conservation-tech-prize-forreforestation-project/ (accessed on 2 April 2021).

174. Aeracoop. Dronecoria: Drone for Forest Restoration. Instructables. 2019. Available online: https://www.instructables.com/ Dronecoria-Drone-for-Forest-Restoration/ (accessed on 7 April 2021).

175. Elumalai, D. Seed Sowing or Tree Planting Drone. Skyfi Education Labs Pvt. Ltd. 2020. Available online: https://www.skyfilabs. $\mathrm{com} /$ project-ideas/seed-sowing-tree-planting-drone (accessed on 10 April 2021).

176. Koranne, A.; Datar, C.; Date, S.; Joglekar, A. Low-cost applications of drones in seed-plantation and plant-health analysis. ICIIIME 2017, 5, 707-713.

177. Niazy, M.M. Improving the Seed Balls via Using the Alginate Microbeads and Drones for Desert Greening and Reduce Deforestation of Earth. 2020. Available online: https://www.researchgate.net/publication/340647618_Improving_the_seed_balls_via_ using_the_Alginate_microbeads_and_Drones_for_desert_greening_and_reduce_deforestation_of_Earth (accessed on 13 January 2021). [CrossRef]

178. Cozens, W. Automated Aerial Seed Planting Using Biodegradable Polymers. Master's Thesis, The University of Waikato, Hamilton, New Zealand, 2019. Available online: https:/ / researchcommons.waikato.ac.nz/handle/10289/12765 (accessed on 13 January 2021).

179. Vovchenko, N.; Novikov, A.; Sokolov, S.; Tishchenko, E. New technology for encapsulating conditioned seeds to increase aerial seeding efficiency. IOP Conf. Ser. Earth Environ. Sci. 2020, 595, 012009. [CrossRef]

180. Fortes, E.P. Seed plant drone for reforestation. Graduate Rev. 2009, 2, 13-26. Available online: https://vc.bridgew.edu/cgi/ viewcontent.cgi?article=1033\&context=grad_rev (accessed on 5 January 2021).

181. Guest, P. Tropical Forests Are Dying. Seed-Slinging Drones Can Save Them. Wired UK. 2019. Available online: https://www. wired.co.uk/article/feature-biocarbon-drones (accessed on 5 April 2021).

182. Posch, M. Planting 20 Million Trees, Using Drones, Cannons, and More Unconventional Ways I Hackaday. Hackaday. 2019. Available online: https:/ /hackaday.com/2019/10/29/planting-20-million-trees-using-drones-cannons-and-more-unconventionalways / (accessed on 8 April 2021).

183. Moynihan, B. Planting Atlantic White Cedar: A Decade Long Partnership Is Returning Native Atlantic White Cedar to Maryland's Eastern Shore. The Nature Conservancy. 2019. Available online: https:/ /www.nature.org/en-us/about-us/where-we-work/ united-states/maryland-dc/stories-in-maryland-dc/planting-atlantic-white-cedar/ (accessed on 28 March 2021).

184. Malmsheimer, R.W.; Heffernan, P.; Brink, S.; Crandall, D.; Deneke, F.; Galik, C.; Gee, E.; Helms, J.A.; McClure, N.; Mortimer, M. Forest management solutions for mitigating climate change in the United States. J. For. 2008, 106, 115-173. 
185. IPCC. Summary for Policymakers. In Climate Change 2014: Mitigation of Climate Change. Contribution of Working Group III to the Fifth Assessment Report of the Intergovernmental Panel on Climate Change; Edenhofer, O.R., Pichs Madruga, Y., Sokona, E., Farahani, S., Kadner, K., Seyboth, A., Adler, I., Baum, S., Brunner, P., Eickemeier, B., et al., Eds.; Cambridge University Press: Cambridge, UK; New York, NY, USA, 2014.

186. Swanston, C.; Brandt, L.A.; Janowiak, M.K.; Handler, S.D.; Butler-Leopold, P.; Iverson, L.; Thompson, F.R., III; Ontl, T.A.; Shannon, P.D. Vulnerability of forests of the Midwest and Northeast United States to climate change. Clim. Chang. 2018, 146, $103-116$. [CrossRef]

187. Thomas, E.; Jalonen, R.; Loo, J.; Boshier, D.; Gallo, L.; Cavers, S.; Bordacs, S.; Smith, P.; Bozzano, M. Genetic considerations in ecosystem restoration using native tree species. For. Ecol. Manag. 2014, 333, 66-75. [CrossRef]

188. Williams, M.I.; Dumroese, R.K. Preparing for climate change: Forestry and assisted migration. J. For. 2013, 111, 287-297. [CrossRef]

189. Schirone, B.; Salis, A.; Vessella, F. Effectiveness of the Miyawaki method in mediterranean forest restoration programs. Landsc. Ecol. Eng. 2011, 7, 81-92. [CrossRef]

190. Fjellheim, H. Global Carbon Markets Hit New Highs, Refinitiv. 2021. Available online: https://www.refinitiv.com/en/resources/ special-report/global-carbon-market-report (accessed on 1 April 2021).

191. China National ETS. China National ETS. International Carbon Action Partnership. 2021. Available online: https: / / icapcarbonaction.com/en/?option=com_etsmap\&task=export\&format=pdf\&layout=list\&systems $\% 5 B \% 5 D=55$ (accessed on 20 March 2021).

192. UK ETS. Guidance: Participate in the UK ETS. Department for Business, Energy and Industrial Strategy. 2020. Available online: https:/ / www.gov.uk/government/publications/participating-in-the-uk-ets/participating-in-the-uk-ets (accessed on $30 \mathrm{March}$ 2021).

193. Climate Action Reserve. 2020. Available online: https://www.climateactionreserve.org/ (accessed on 1 April 2021).

194. UASWeekly.com. Droneseed is First in U.S. to Receive Approval from FAA for Post-Wildfire Reforestation in California. 2021. Available online: https:/ / uasweekly.com/2020/10/08/droneseed-is-first-in-u-s-to-receive-approval-from-faa-for-postwildfire-reforestation-in-california /?utm_source=rss\&utm_medium=rss\&utm_campaign=droneseed-is-first-in-u-s-to-receiveapproval-from-faa-for-post-wildfire-reforestation-in-california\&utm_term=2020-10-09 (accessed on 29 March 2021).

195. Lin, C.F.; Lin, T.J.; Liao, W.S.; Lan, H.; Lin, J.Y.; Chiu, C.H.; Danner, A. Solar power can substantially prolong maximum achievable airtime of quadcopter drones. Adv. Sci. 2020, 7, 2001497. [CrossRef]

196. Apeland, J.; Pavlou, D.; Hemmingsen, T. Suitability analysis of implementing a fuel cell on a multirotor drone. J. Aerosp. Technol. Manag. 2020, 12. [CrossRef]

197. Bai, M.; Yang, W.; Song, D.; Kosuda, M.; Szabo, S.; Lipovsky, P.; Kasaei, A. Research on energy management of hybrid unmanned aerial vehicles to improve energy-saving and emission reduction performance. Int. J. Environ. Res. Public Health 2020, $17,2917$. [CrossRef] [PubMed]

198. Nichols, G. How Wireless Charging could Unlock Commercial Drone Potential. ZDNet. 2021. Available online: https://www. zdnet.com/article/how-wireless-charging-could-unlock-commercial-drone-potential/ (accessed on 28 March 2021).

199. Yamunathangam, D.; Shanmathi, J.; Caviya, R.; Saranya, G. Payload manipulation for seed sowing unmanned aerial vehicle through interface with pixhawk flight controller. In Proceedings of the 2020 Fourth International Conference on Inventive Systems and Control (ICISC), Coimbatore, Tamilnadu, India, 8-10 January 2020; pp. 931-934. [CrossRef]

200. Choudhry, H.; O’Kelly, G. Precision Forestry: A Revolution in the Woods. 2018. Available online: https://www.mckinsey.com/ industries/paper-forest-products-and-packaging/our-insights/precision-forestry-a-revolution-in-the-woods (accessed on 29 March 2021).

201. Dubayah, R.; Blair, J.B.; Goetz, S.; Fatoyinbo, L.; Hansen, M.; Healey, S.; Hofton, M.; Hurtt, G.; Kellner, J.; Luthcke, S.; et al. The Global Ecosystem Dynamics Investigation: High-resolution laser ranging of the Earth's forests and topography. Sci. Remote Sens. 2018, 1, 100002. [CrossRef]

202. Fisher, J.B.; Lee, B.; Purdy, A.J.; Halverson, G.H.; Dohlen, M.B.; Cawse-Nicholson, K. ECOSTRESS: NASA's Next Generation Mission to measure evapotranspiration from the International Space Station. Water Resour. Res. 2020, 56, e2019WR02. [CrossRef]

203. Goodbody, T.R.; Coops, N.C.; Hermosilla, T.; Tompalski, P.; Crawford, P. Assessing the status of forest regeneration using digital aerial photogrammetry and unmanned aerial systems. Int. J. Remote Sens. 2018, 39, 5246-5264. [CrossRef]

204. Cardil, A.; Otsu, K.; Pla, M.; Silva, C.A.; Brotons, L. Quantifying pine processionary moth defoliation in a pine-oak mixed forest using unmanned aerial systems and multispectral imagery. PLoS ONE 2019, 14, e021. [CrossRef]

205. Ashraf, A. ForresOn—End-to-End Mass Scale Precision Planting. One Year of Uplink. Available online: https://uplink.weforum. org/uplink/s/uplink-contribution/a012o00001OSSvJAAX/forreson-endtoend-mass-scale-precision-planting (accessed on 8 April 2020).

206. Crebar, M. A Drone that Sprays and Spreads I AgTech Finder. Agtechfinder. 2020. Available online: https://agtechfinder.com/ agtech-info/drone-sprays-and-spreads (accessed on 8 April 2021).

207. Karpowicz, J. TruWeather Proves Why the Drone Industry Need Better Weather Data. Commercial UAV News. 2018. Available online: https:/ / www.commercialuavnews.com/infrastructure/truweather-drone-industry-better-weather-data (accessed on 1 April 2021). 
208. Urzedo, D.I.D.; Piña-Rodrigues, F.; Feltran-Barbieri, R.; Junqueira, R.G.; Fisher, R. Seed networks for upscaling forest landscape restoration: Is it possible to expand native plant sources in Brazil? Forests 2020, 11, 259. [CrossRef]

209. Sidik, F.; Supriyanto, B.; Krisnawati, H.; Muttaqin, M.Z. Mangrove conservation for climate change mitigation in Indonesia. Wiley Interdiscip. Rev. Clim. Chang. 2018, 9, e529. [CrossRef]

210. McIvor, A.L.; Spencer, T.; Möller, I.; Spalding, M. Storm surge reduction by mangroves. Natural coastal protection series: Report 2. Cambridge Coastal Research Unit Working Paper 41, 35. The Nature Conservancy and Wetlands International. ISSN $2050-7941$. Available online: http:/ / www.naturalcoastalprotection.org/documents/storm-surge-reduction-by-mangroves (accessed on 5 January 2021).

211. Menéndez, P.; Losada, I.J.; Torres-Ortega, S.; Narayan, S.; Beck, M.W. The global flood protection benefits of mangroves. Sci. Rep. 2020, 10, 1-11. [CrossRef]

212. Othman, M.A. Value of mangroves in coastal protection. Hydrobiologia 1994, 285, 277-282. [CrossRef]

213. Geronimo, F. We'll Depend More on Drones to Reforest Our Planet Because It's Faster. Earth Buddies. 2020. Available online: https:/ / earthbuddies.net/drones-reforestation/ (accessed on 8 April 2021).

214. Navarro, A.; Young, M.; Allan, B.; Carnell, P.; Macreadie, P.; Ierodiaconou, D. The application of Unmanned Aerial Vehicles (UAVs) to estimate above-ground biomass of mangrove ecosystems. Remote Sens. Environ. 2020, 272, 111747. [CrossRef]

215. Ruwaimana, M.; Satyanarayana, B.; Otero, V.; Muslim, A.; Syafiq, A.; Ibrahim, S.; Raymeakers, D.; Koedam, N.; Dahdouh-Guebas, F. The advantages of using drones over space-borne imagery in the mapping of mangrove forests. PLoS ONE 2018, 13, e0200288. [CrossRef]

216. Yaney-Keller, A.; Santidrián Tomillo, P.; Marshall, J.M.; Paladino, F.V. Using Unmanned Aerial Systems (UAS) to assay mangrove estuaries on the Pacific coast of Costa Rica. PLoS ONE 2019, 14, e0217310. [CrossRef]

217. Ridge, J.T.; Johnston, D.W. Unoccupied Aircraft Systems (UAS) for marine ecosystem restoration. Front. Mar. Sci. 2020, 7. [CrossRef]

218. FAO. E-Agriculture in Action. Drones for Agriculture. Food and Agriculture Organization of the United Nations, Rome, Italy. 2018. Available online: http:/ / www.fao.org/3/i8494en/i8494en.pdf (accessed on 29 March 2021).

219. Sharma, M. How Drones Are Being Used to Combat COVID-19. 2020. Available online: https://www.geospatialworld.net/ blogs/how-drones-are-being-used-to-combat-covid-19/ (accessed on 30 March 2021).

220. Drone Reforestation-Lord of the Trees. Available online: https:/ /lordofthetrees.org/pages/drone-reforestation (accessed on 3 April 2021).

221. Landis, J.; Agnew, O. These Drones Plant Trees by Firing Seed Pods at the Ground. Popular Science. 2018. Available online: https:/ / www.popsci.com/drones-plant-trees/ (accessed on 8 April 2021).

222. FAO; UNEP. The State of the World's Forests 2020, Forests 2020, Biodiversity, and People; FAO and UNEP: Rome, Italy, 2020. [CrossRef]

223. The Nature Conservancy. Plant a Billion Trees. Available online: https:/ /www.nature.org/en-us/get-involved/how-to-help/ plant-a-billion/ (accessed on 28 March 2021).

224. Natural Resources Canada. Minister O'Regan Launches Canada's Plan to Plant Two Billion Trees. 2020. Available online: https: / / www.canada.ca/en/natural-resources-canada/news/2020/12/minister-oregan-launches-canadas-plan-to-planttwo-billion-trees.html (accessed on 29 March 2021).

225. Faruqi, S.; Wu, A.; Brolis, E.; Ortega, A.A.; Batista, A. The Business of Planting Trees: A Growing Investment Opportunity. World Resource Institute, Washington, USA. 2018. Available online: https://www.nature.org/content/dam/tnc/nature/en/ documents/Business_of_Planting_Trees_Report.pdf (accessed on 4 January 2021).

226. Formisani, L. Replanting Trees with Drones. Eni. 2020. Available online: https://www.eni.com/en-IT/technologies/ reforestation-drones.html (accessed on 2 April 2021).

227. European Commission. Innovative Drone Technology to Tackle Deforestation. European Commission. 2016. Available online: https: / / cordis.europa.eu/article/id/119479-innovative-drone-technology-to-tackle-deforestation (accessed on 6 April 2021).

228. SYSTEMIQ. Biocarbon Engineering Receives US\$2.5 Million in Seed Investment. 2016. Available online: https:/ /www.systemiq. earth/biocarbon-engineering/ (accessed on 8 April 2021).

229. Sanquetta, C.R.; Dalla Corte, A.P.; Maas, G.B. The role of forests in climate change. Quebracho 2011, 19, 84-96.

230. Busch, J. Reforestation Can Help Reverse the Climate and Extinction Crises. It's Cost-Effective too. Earth Innovation Institute. 2019. Available online: https:/ / earthinnovation.org/2019/05/reforestation-can-help-reverse-the-climate-and-extinction-crises / (accessed on 29 March 2021).

231. Holl, K.D.; Brancalion, P.H. Tree planting is not a simple solution. Science 2020, 368, 580-581. [CrossRef]

232. Mandel, K. Planting Trees Sounds Like a Simple Climate fix. It's Anything But: We Need Forests to Fight Climate Change, but Planting Trees to Cancel out Emissions Is a Lot Harder than It Looks. Huffpost. 2021. Available online: https:/ / www.huffpost.com/entry / planting-trees-not-simple-climate-fix_n_601c1627c5b6c0af54d17e98?s_src=NewSch. WJEMSA2103NPNZNZZE03Z00-ZZZZZ-ST00\&lu=7213892\&src=e.ch_wv.eg.x.gpn.0321.n.sas.trd (accessed on 1 April 2021).

233. Rina, S. Khan, Record Locust Swarms Hint at What's to Come with Climate Change. 2016. Available online: https:/ / eos.org/ articles / record-locust-swarms-hint-at-whats-to-come-with-climate-change (accessed on 1 April 2021).

234. Yong, E. What Wildlife Shows Don't Tell You About African Wild Dogs. National Geographic. 2020. Available online: https: //www.nationalgeographic.com/science/article/what-wildlife-shows-dont-tell-you-about-african-wild-dogs (accessed on 1 April 2021). 
235. Dwyer, A. How to Plant Trees: A Guide to the Latest Tree-Planting Technologies. Landscape News. 2020. Available online: https:/ / news.globallandscapesforum.org/47093/drones-dogs-cocoons-its-a-new-age-for-tree-planting/ (accessed on 1 April 2021).

236. Lee, DroneSeed Uses Drones in Post-Wildfire re-Planting Project. UAV Coach. 2018. Available online: https://uavcoach.com/ droneseed (accessed on 10 April 2021).

237. Evans, S.; Gabbatiss, J. Coronavirus: Tracking How the World's 'Green Recovery' Plans Aim to Cut Emissions. Carbon Brief. 2020. Available online: https:/ / www.carbonbrief.org/coronavirus-tracking-how-the-worlds-green-recovery-plans-aim-to-cutemissions (accessed on 29 March 2021).

238. Biello, D. Gigalopolises: Urban Land Area May Triple by 2030. Scientific American. 2012. Available online: https://www. scientificamerican.com/article/cities-may-triple-in-size-by-2030/ (accessed on 28 March 2021).

239. Watt, R. Carbon Offsets Offer a Fantasy of Capitalism without Crises. Resilience. 2021. Available online: https://www.resilience. org/stories / 2021-03-17/ carbon-offsets-offer-a-fantasy-of-capitalism-without-crises/ (accessed on 30 March 2021). 